\title{
High spatial resolution analysis of the iron oxidation state in silicate glasses using the electron probe o
}

\author{
ERy C. HugheS ${ }^{1, *}$, Ben Buse ${ }^{1}$, Stuart L. Kearns ${ }^{1}$, Jon D. Blundy ${ }^{1}$, GeOFF KILGOUR ${ }^{2}$, \\ HEIDY M. MADER ${ }^{1}$, RICHARD A. BROOKER ${ }^{1}$, ROBERT BALZER ${ }^{3}$, ROMAN E. BOTCHARNIKOV ${ }^{3,4}$, \\ DANILO Di GENOVA ${ }^{1}$, RENAT R. ALMEEV ${ }^{3}$, AND JENNY M. RIKER ${ }^{1}$
}

${ }^{1}$ School of Earth Sciences, University of Bristol, Wills Memorial Building, Queens Road, Bristol BS8 1RJ, U.K. ${ }^{2}$ GNS Science, Wairakei Research Centre, 114 Karetoto Road, RD4, Taupo 3384, New Zealand

${ }^{3}$ Leibniz Universität Hannover, Institut für Mineralogie, Callinstrasse 3, D-30167, Hannover, Germany

${ }^{4}$ Institute für Geowissenschaften, Johannes Gutenberg Universität Mainz, J.-J.-Becher-Weg 21, 55128 Mainz, Germany

\begin{abstract}
The iron oxidation state in silicate melts is important for understanding their physical properties, although it is most often used to estimate the oxygen fugacity of magmatic systems. Often high spatial resolution analyses are required, yet the available techniques, such as $\mu$ XANES and $\mu$ Mössbauer, require synchrotron access. The flank method is an electron probe technique with the potential to measure Fe oxidation state at high spatial resolution but requires careful method development to reduce errors related to sample damage, especially for hydrous glasses. The intensity ratios derived from measurements on the flanks of $\mathrm{Fe} L \alpha$ and $\mathrm{Fe} L \beta \mathrm{X}$-rays $\left(\mathrm{Fe} L \beta_{\mathrm{f}} / \mathrm{Fe} L \alpha_{\mathrm{f}}\right)$ over a time interval (time-dependent ratio flank method) can be extrapolated to their initial values at the onset of analysis. We have developed and calibrated this new method using silicate glasses with a wide range of compositions (43-78 $\mathrm{wt} \%$ $\mathrm{SiO}_{2}, 0-10 \mathrm{wt} \% \mathrm{H}_{2} \mathrm{O}$, and $2-18 \mathrm{wt} \% \mathrm{FeO}_{\mathrm{T}}$, which is all $\mathrm{Fe}$ reported as $\mathrm{FeO}$ ), including 68 glasses with known $\mathrm{Fe}$ oxidation state. The $\mathrm{Fe}$ oxidation state $\left(\mathrm{Fe}^{2+} / \mathrm{Fe}_{\mathrm{T}}\right)$ of hydrous $\left(0-4 \mathrm{wt} \% \mathrm{H}_{2} \mathrm{O}\right)$ basaltic (43-56 wt $\% \mathrm{SiO}_{2}$ ) and peralkaline $\left(70-76 \mathrm{wt} \% \mathrm{SiO}_{2}\right.$ ) glasses with $\mathrm{FeO}_{\mathrm{T}}>5 \mathrm{wt} \%$ can be quantified with a precision of $\pm 0.03\left(10 \mathrm{wt} \% \mathrm{FeO}_{\mathrm{T}}\right.$ and $\left.0.5 \mathrm{Fe}^{2+} / \mathrm{Fe}_{\mathrm{T}}\right)$ and accuracy of \pm 0.1 . We find basaltic and peralkaline glasses each require a different calibration curve and analysis at different spatial resolutions ( $\sim 20$ and $\sim 60 \mu \mathrm{m}$ diameter regions, respectively). A further 49 synthetic glasses were used to investigate the compositional controls on redox changes during electron beam irradiation, where we found that the direction of redox change is sensitive to glass composition. Anhydrous alkali-poor glasses become reduced during analysis, while hydrous and/or alkali-rich glasses become oxidized by the formation of magnetite nanolites identified using Raman spectroscopy. The rate of reduction is controlled by the initial oxidation state, whereas the rate of oxidation is controlled by $\mathrm{SiO}_{2}, \mathrm{Fe}$, and $\mathrm{H}_{2} \mathrm{O}$ content.

Keywords: Electron probe microanalysis (EPMA), iron (Fe) oxidation state, flank method, electron beam damage, silicate glass, oxidation, reduction, Raman spectroscopy
\end{abstract}

\section{INTRODUCTION}

Oxygen fugacity is an important control on the chemical and physical properties of silicate melts, the stability of magmatic phases, and the multiphase rheology of magmas (e.g., Hamilton et al. 1964; Dingwell and Virgo 1987; Kress and Carmichael 1991; Vicenzi et al. 1994; Bouhifd et al. 2004; Wilke 2005). It also determines the valence state of multivalent elements, such as $\mathrm{Fe}, \mathrm{Mn}, \mathrm{Cr}, \mathrm{V}, \mathrm{Ce}, \mathrm{Eu}$, and $\mathrm{S}$, and hence the ratio of oxidized to reduced species in the glasses quenched from melts provides a proxy for oxygen fugacity during natural processes and laboratory experiments (e.g., Carmichael 1991; Kress and Carmichael 1991; Herd 2008). Many petrological and volcanological applications, such as analysis of glassy melt inclusions in minerals from volcanic rocks or interstitial glass

\footnotetext{
* E-mail: ery.hughes@bristol.ac.uk

of Open access: Article available to all readers online. This article is CC-BY.
}

in natural and experimental vesiculated and/or partially crystalline samples, require measurements at high spatial resolutions.

There are various techniques for quantifying the Fe oxidation state of silicate glasses, with trade-offs between resolution, error, sample preparation requirements, necessity for standards, and instrument accessibility (see McCammon 1999). Wet chemistry is a destructive bulk technique, requiring a minimum of $5 \mathrm{mg}$ of material (e.g., Schuessler et al. 2008), which does not require standards but some expertise. Synchrotron-based absorption techniques, such as $\mu$ XANES $(>2 \times 2 \mu \mathrm{m}$, e.g., Cottrell et al. 2018) and $\mu$ Mössbauer $(>10 \times 5 \mu \mathrm{m}$, e.g., Potapkin et al. 2012) allow high spatial resolution analysis, but the need for access to synchrotron facilities limits their utility. Also, $\mu \mathrm{XANES}$ can oxidize $\mathrm{Fe}$ in hydrous glasses during analysis, producing erroneous Fe oxidation state values (Cottrell et al. 2018). Raman spectroscopy also has a high spatial resolution ( $1 \mu \mathrm{m}$ diameter), but has lower sensitivity for basaltic compositions and problems related to background fluorescence (e.g., Di 
Muro et al. 2009; Di Genova et al. 2016). Electron energy loss spectroscopy (EELS) would offer a superior spatial resolution (nanometer), but standards are inhomogeneous at this scale and beam damage is significant (Burgess et al. 2016).

Conversely, the electron probe is widely available and has the potential for routine analysis of Fe oxidation state in geological materials (mainly garnet and amphibole) at high spatial resolution (Hofer et al. 1994; Enders et al. 2000; Hofer and Brey 2007; Creighton et al. 2009, 2010; Malaspina et al. 2010; Lamb et al. 2012; Matjuschkin et al. 2014) and also glasses (Fialin et al. 2001, 2004, 2011). Typically, the electron probe uses the intensity of emitted characteristic X-rays to quantify chemical composition, such as $\mathrm{Fe} K \alpha$ to quantify Fe concentration (Fig. 1a), however various other factors can affect the intensity of characteristic X-rays. The $\mathrm{Fe} L \alpha$ and $\mathrm{Fe} L \beta$ lines are sensitive to the Fe oxidation state as their X-ray generation involves outer shell electrons (3d) affected by chemical bonding (Fig. 1a) (Gopon et al. 2013). The energy of X-ray emission and absorption associated with the $\mathrm{Fe} L$ lines is very similar, which leads to self-absorption. The $\mathrm{Fe} L \alpha$ and $\mathrm{Fe} L \beta$ peaks coincide with the $L_{3}$ and $L_{2}$ absorption edges, respectively, and hence are distorted by them, resulting in asymmetric peak shapes and peak shifts due to the differing amounts of absorption on each side of the absorption edges (Smith and O'Nions 1971). The wavelength of the energy of the absorption edges shifts due to changes in the coordination and oxidation state of Fe (de Groot 2001; Hofer and Brey 2007). The $L_{3}$ absorption edge shifts more than the $L_{2}$ absorption edge, resulting in greater changes to the $\mathrm{Fe} L \alpha$ peak than the $\mathrm{Fe} L \beta$ (Hofer and Brey 2007). Thus, for a given chemical system (e.g., garnet, olivine, silicate glass), the $\mathrm{Fe} L \alpha$ and $\mathrm{Fe} L \beta$ peak positions and intensities vary depending on Fe concentration, oxidation state, and coordination (Fig. 1b; Hofer and Brey 2007).
There are two EPMA methods that exploit variations in $\mathrm{Fe} L \alpha$ and $\mathrm{Fe} L \beta$ to quantify Fe oxidation state (Fig. 1b). The peak shift method uses the linear relationship between the wavelength of the $\mathrm{Fe} L \alpha$ peak with $\mathrm{Fe}$ oxidation state at a given $\mathrm{FeO}_{\mathrm{T}}$ (Hofer et al. 1994; Fialin et al. 2004) (Fig. 1b). To measure the $\mathrm{Fe} L \alpha$ peak position, wavescans across the $\mathrm{Fe} L \alpha$ peak are collected and a peak-fitting algorithm is applied to locate its wavelength. This method has been applied to silicate glasses with a statistical error on $\mathrm{Fe}^{2+} / \mathrm{Fe}_{\mathrm{T}}$ of \pm 0.05 , although the error on individual analyses was greater (Fialin et al. 2004). Alternatively, the flank method uses changes in the wavelength and intensity of both the $\mathrm{Fe} L \alpha$ and $\mathrm{Fe} L \beta$ peaks by measuring the intensity ratio of positions on the low-wavelength flank of $\mathrm{Fe} L \alpha\left(\mathrm{Fe} L \alpha_{\mathrm{f}}\right)$ and high-wavelength flank of $\mathrm{Fe} L \beta\left(\mathrm{Fe} L \beta_{\mathrm{f}}\right)$, termed $\mathrm{Fe} L \beta_{\mathrm{f}} / \mathrm{Fe} L \alpha_{\mathrm{f}}$ (Hofer et al. 1994; Hofer 2002; Hofer and Brey 2007) (Fig. 1b). These flank positions coincide with the $L_{2}$ and $L_{3}$ absorption edges and, as the $\mathrm{Fe}^{2+}$ content changes, the $L_{3}$ absorption edge shifts. The sensitivity of the flank method results from the opposite sense of intensity change at each of the flank positions, as $\mathrm{Fe} L \alpha_{\mathrm{f}}$ is on the high-absorption side of the $L_{3}$ absorption edge, whereas $\mathrm{Fe} L \beta_{\mathrm{f}}$ is on the low-absorption side of the $L_{2}$ absorption edge, which utilizes changes in both peak position and intensities (Hofer et al. 1994). Optimum flank positions can be found by collecting absorption spectra or using the maximum and minimum in the difference spectrum between samples with different $\mathrm{Fe}$ concentration and oxidation states (Fig. 1b, Hofer and Brey 2007). The $\mathrm{Fe} L \beta_{\mathrm{f}} / \mathrm{Fe} L \alpha_{\mathrm{f}}$ intensity ratio depends primarily on total ferrous iron $\left(\mathrm{Fe}^{2+}\right)$, with a secondary dependence on total $\mathrm{Fe}\left(\mathrm{Fe}_{\mathrm{T}}\right)$, hence

$$
\mathrm{Fe}^{2+}=A+B \cdot\left(\mathrm{Fe} L \beta_{\mathrm{f}} / \mathrm{Fe} L \alpha_{\mathrm{f}}\right)+C \cdot \mathrm{Fe}_{\mathrm{T}}+D \cdot \mathrm{Fe}_{\mathrm{T}} \cdot\left(\mathrm{Fe} L \beta_{\mathrm{f}} / \mathrm{Fe} L \alpha_{\mathrm{f}}\right)
$$

where $A, B, C$, and $D$ are fitting coefficients (Hofer and Brey 2007). The flank method has greater sensitivity than the peak
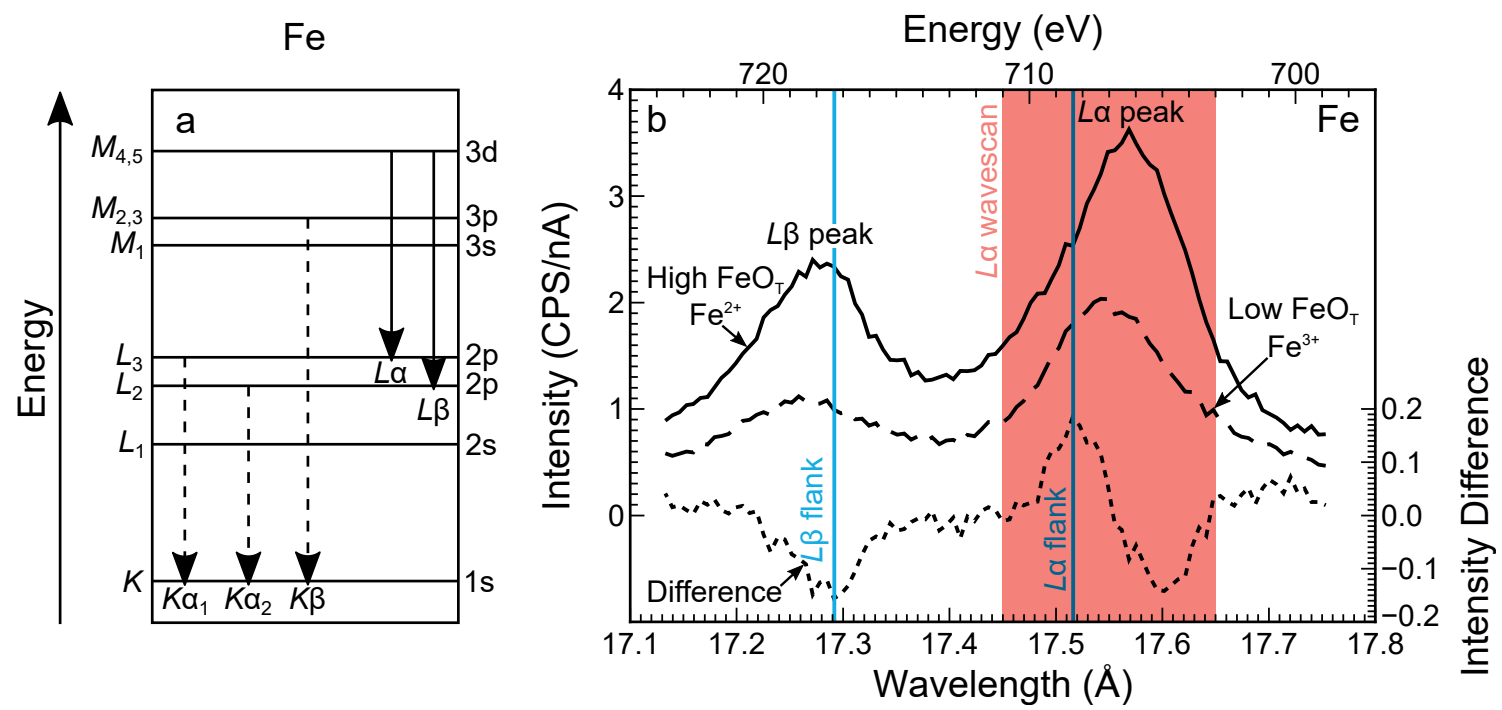

FIGURE 1. (a) Energy level diagram of the electron transitions that generate characteristic Fe X-rays, and (b) wavelength spectra of the Fe $L \alpha$ and $\mathrm{Fe} L \beta$ peaks for a reduced, high $\mathrm{FeO}_{\mathrm{T}}$ (solid, AR19) and oxidized, low $\mathrm{FeO}_{\mathrm{T}}$ (dashed, AR14) silicate glass (Tables 1 and 2) plotted using the left-hand axes, and the difference spectrum (dotted, calculated once the wavescans are normalized to their maximum Fe $L \alpha$ peak intensity) plotted using the right-hand axes. The red box indicates the wavelengths measured for the peak shift method (Fe $L \alpha$ wavescan). The blue vertical lines indicate optimum wavelength positions measured for the flank method, which correspond to the maximum and minimum of the difference spectrum. 
shift method and does not require wavescans becasue measurements are made at two specific, pre-defined wavelengths (Hofer et al. 1994; Zhang et al. 2018). This method has been applied to some mineral groups (e.g., garnet, spinel) with an error on $\mathrm{Fe}^{2+} / \mathrm{Fe}_{\mathrm{T}}$ of \pm 0.02 (Hofer and Brey 2007) and silicate glasses to within \pm 0.1 (Zhang et al. 2018).

The $\mathrm{Fe} L$ lines have low intensity and therefore high beam currents and/or long count times are required to record them. Silicate glasses are typically unstable under these conditions, leading to changes in Fe oxidation state during analysis (Fialin et al. 2004, 2011; Fialin and Wagner 2012; Zhang et al. 2018). Similar problems have also been observed for Fe in amphiboles (Wagner et al. 2008; Lamb et al. 2012) and S in silicate glasses and anhydrite (Wallace and Carmichael 1994; Rowe et al. 2007; Klimm et al. 2012). Fialin and Wagner (2012) observed two competing mechanisms of redox change during electron beam irradiation of alkali-bearing silicate glasses leading to either oxidation or reduction. As glasses are insulators, electrons are trapped within the subsurface during electron beam irradiation, causing a region of negative charge to buildup at depth in the sample, even with a conductive coat (e.g., Cazaux 1996). Alkali ions (predominantly $\mathrm{Na}^{+}$but also $\mathrm{K}^{+}$) migrate toward the region of negative charge (e.g., Humphreys et al. 2006) leaving behind interstitial $\mathrm{O}^{2-}$ that migrates and either outgasses or combines with two $\mathrm{FeO}$ precipitating $\mathrm{Fe}_{2} \mathrm{O}_{3}$, thus causing oxidation (e.g., Lineweaver 1963). This is different from oxidation processes driven by changes in oxygen fugacity. For basaltic glasses, $\mathrm{Fe}^{3+}$ is stabilized by the migration of $\mathrm{Na}^{+}$and $\mathrm{K}^{+}$toward them preventing $\mathrm{Fe}_{2} \mathrm{O}_{3}$ precipitation (Cooper et al. 1996). Concurrently, during electron beam irradiation electrons move away from the negatively charged region from $\mathrm{O}$ to $\mathrm{Fe}^{3+}$ sites resulting in net reduction (Nishida 1995).

To minimize beam damage and prevent redox changes a sample can be moved during analysis, which reduces the electron dose per unit area (Metrich and Clocchiatti 1996; Rowe et al. 2007; Fialin et al. 2011; Zhang et al. 2018). Unfortunately, this requires large regions of glass for analysis making it unfeasible for analyzing small areas, such as melt inclu-

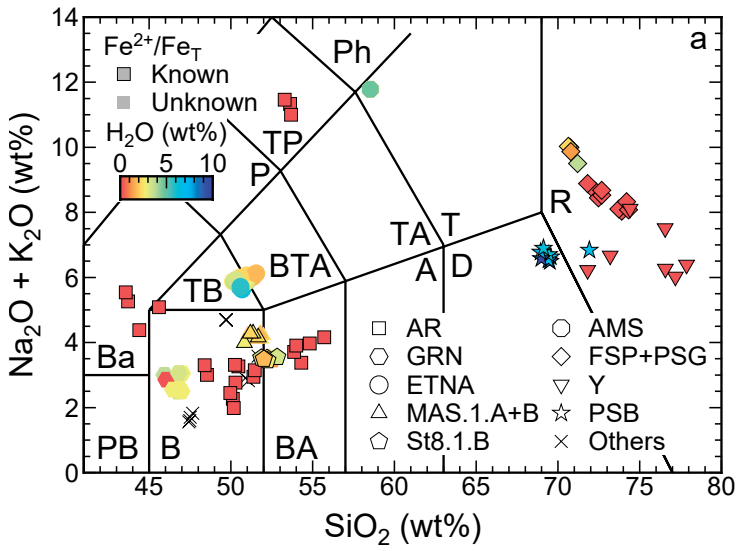

sions and interstitial glasses. Therefore, we adapt the flank method for high spatial resolution analysis of silicate glasses due to its greater sensitivity and the ability to measure at single spectrometer positions (Hofer et al. 1994). This is important because it is easier to measure time-dependent changes at specific wavelengths rather than using wavescans, as required for the peak shift method. We measured $\mathrm{Fe} L \beta_{\mathrm{f}} / \mathrm{Fe} L \alpha_{\mathrm{f}}$ over time, based on the time-dependent intensity (TDI) technique first developed for alkali migration during EPMA of glasses by Nielsen and Sigurdsson (1981). $\mathrm{Fe} L \beta_{\mathrm{f}} / \mathrm{Fe} L \alpha_{\mathrm{f}}$ is extrapolated to time zero to correct for changes over time, which we refer to as the Time-Dependent Ratio (TDR) correction, comparable to TDI corrections for alkalis. Due to the small sample size of silicate glasses analyzed by Fialin and Wagner (2012) and Zhang et al. (2018), the controls on Fe redox processes during electron beam irradiation have not been explored and, crucially, few hydrous glasses have been analyzed. Therefore, we also investigate the compositional and analytical controls on $\mathrm{Fe}$ redox changes.

\section{SAMPLES}

Silicate glasses of known (68 samples) and unknown (47 samples) Fe oxidation state from various studies were mounted in epoxy and carbon coated ( $15 \mathrm{~nm}$ thickness). The sample set covers a wide compositional range (anhydrous normalized $\mathrm{SiO}_{2}$ $43-78 \mathrm{wt} \%$, total alkalis $\left(\mathrm{Na}_{2} \mathrm{O}+\mathrm{K}_{2} \mathrm{O}\right) 1-12 \mathrm{wt} \%$, and $\mathrm{H}_{2} \mathrm{O} 0-10$ wt $\%$; Fig. 2a and Table 1), which are used to investigate the effect of composition on Fe oxidation state changes during analysis. Silicate glasses of known Fe oxidation state (independently measured using wet chemistry, Mössbauer or $\mu$ XANES), spanning $0.1-1.0 \mathrm{Fe}^{2+} / \mathrm{Fe}_{\mathrm{T}}$ and $2-18 \mathrm{wt} \% \mathrm{FeO}_{\mathrm{T}}$ (Fig. 2b), are used to calibrate the technique.

There are 16 suites of experimental silicate glasses that have different average glass compositions with variable Fe oxidation state and/or $\mathrm{H}_{2} \mathrm{O}$. The normalized (volatile-free) average glass compositions, which are either taken from the literature or measured using EPMA (see Supplementary Material ${ }^{1}$ for details and individual sample compositions) are given in Table 1. AR

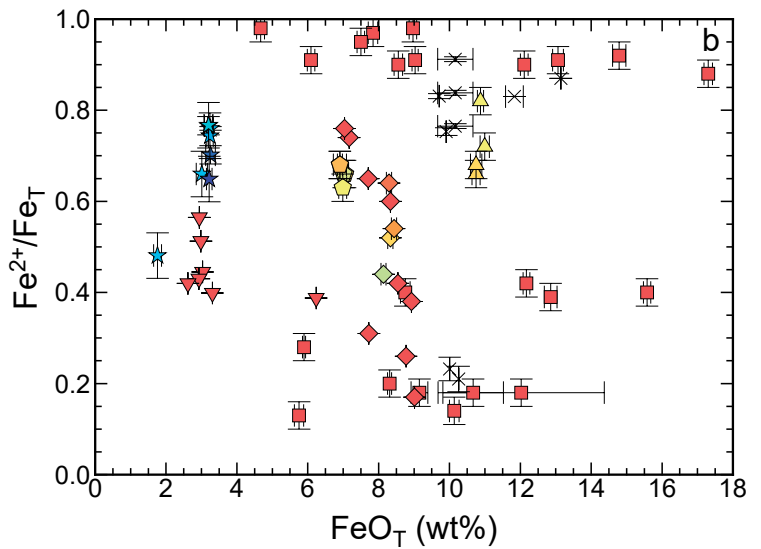

FigUre 2. (a) Total alkalis $\left(\mathrm{Na}_{2} \mathrm{O}+\mathrm{K}_{2} \mathrm{O}\right)$ against silica (where $\mathrm{SiO}_{2}, \mathrm{Na}_{2} \mathrm{O}$, and $\mathrm{K}_{2} \mathrm{O}$ are normalized to the volatile-free total), and (b) $\mathrm{Fe}^{2+} / \mathrm{Fe}_{\mathrm{T}}$ against $\mathrm{FeO}_{\mathrm{T}}$ for samples with known $\mathrm{Fe}$ oxidation state. Symbol shape indicates glass composition (Table 1), color indicates $\mathrm{H}_{2} \mathrm{O}$ content, and a black outline indicates known Fe oxidation state; those without an outline have unknown Fe oxidation state. TAS classification abbreviations: PB = picrobasalt, $\mathrm{B}=$ basalt, $\mathrm{BA}=$ basaltic andesite, $\mathrm{A}=$ andesite, $\mathrm{D}=$ dacite, $\mathrm{TB}=$ trachybasalt, $\mathrm{BTA}=$ basaltic trachyandesite, $\mathrm{TA}=$ trachyandesite, $\mathrm{T}=$ trachyte, $\mathrm{R}=$ rhyolite, $\mathrm{Ba}=$ basanite, $\mathrm{P}=$ phonotephrite, $\mathrm{TP}=$ tephriphonolite, and $\mathrm{Ph}=$ phonolite. 
TABLE 1. Normalized (volatile-free), average glass composition for the suites of experimental silicate glasses

\begin{tabular}{|c|c|c|c|c|c|c|c|c|}
\hline No. & $\begin{array}{c}\text { AR-KLA-1-6-22 } \\
4\end{array}$ & $\begin{array}{l}\text { AR-SC1 } \\
4\end{array}$ & $\begin{array}{c}\text { AR-140ox } \\
3\end{array}$ & $\begin{array}{c}\text { AR-LS } \\
4\end{array}$ & $\begin{array}{c}\text { AR-PF22 } \\
3\end{array}$ & $\begin{array}{c}\text { AR-BezBA } \\
4\end{array}$ & $\begin{array}{c}\text { GRN } \\
10\end{array}$ & $\begin{array}{c}\text { ETNA } \\
24\end{array}$ \\
\hline $\mathrm{SiO}_{2}$ & 44.32 & 49.42 & 50.08 & 51.85 & 53.53 & 54.60 & 46.66 & 50.75 \\
\hline $\mathrm{TiO}_{2}$ & 3.91 & 2.91 & 0.99 & 3.51 & 1.60 & 0.99 & 1.00 & 1.72 \\
\hline $\mathrm{Al}_{2} \mathrm{O}_{3}$ & 13.24 & 15.37 & 15.83 & 12.02 & 19.66 & 17.53 & 13.55 & 17.63 \\
\hline $\mathrm{FeO}_{\mathrm{T}}$ & 10.96 & 11.09 & 8.68 & 15.04 & 5.45 & 7.92 & 9.60 & 10.03 \\
\hline $\mathrm{MnO}$ & 0.20 & 0.00 & 0.17 & 0.33 & 0.17 & 0.18 & 0.20 & 0.33 \\
\hline $\mathrm{MgO}$ & 9.20 & 6.71 & 9.81 & 4.22 & 2.88 & 5.92 & 12.96 & 6.12 \\
\hline $\mathrm{CaO}$ & 8.76 & 11.39 & 12.11 & 9.30 & 4.97 & 8.56 & 13.05 & 7.02 \\
\hline $\mathrm{Na}_{2} \mathrm{O}$ & 2.99 & 2.78 & 2.16 & 2.93 & 7.49 & 2.99 & 2.16 & 4.05 \\
\hline $\mathrm{K}_{2} \mathrm{O}$ & 0.95 & 0.31 & 0.07 & 0.26 & 3.78 & 0.95 & 0.58 & 1.85 \\
\hline $\mathrm{P}_{2} \mathrm{O}_{5}$ & 0.16 & 0.03 & 0.08 & 0.54 & 0.48 & 0.16 & 0.24 & 0.50 \\
\hline $\mathrm{H}_{2} \mathrm{O}$ & 0 & 0 & 0 & 0 & 0 & 0 & $0.28-3.50^{a}$ & $1.58-6.07^{\mathrm{a}}$ \\
\hline $\mathrm{Fe}^{2+} / \mathrm{Fe}_{\mathrm{T}}$ & $0.14-0.98^{c}$ & $0.19-0.95^{c}$ & $0.18-0.97^{c}$ & $0.18-0.92^{c}$ & $0.13-0.98^{c}$ & $0.20-0.91^{c}$ & e & n.d. \\
\hline & MAS.1.A & MAS.1.B & St8.1.B & AMS & FSP & PSG & Y & PSB \\
\hline No. & 6 & 6 & 8 & 3 & 9 & 4 & 7 & 8 \\
\hline $\mathrm{SiO}_{2}$ & 50.86 & 50.84 & 51.86 & 57.72 & 73.16 & 70.84 & 75.37 & 69.61 \\
\hline $\mathrm{TiO}_{2}$ & 1.17 & 1.18 & 0.86 & 0.39 & 0.43 & 0.50 & 0.17 & 0.35 \\
\hline $\mathrm{Al}_{2} \mathrm{O}_{3}$ & 18.91 & 18.76 & 19.13 & 18.40 & 8.95 & 9.24 & 12.25 & 16.06 \\
\hline $\mathrm{FeO}_{\mathrm{T}}$ & 11.18 & 11.19 & 7.53 & 4.51 & 8.14 & 8.49 & 3.43 & 3.30 \\
\hline $\mathrm{MnO}$ & n.d. & n.d. & n.d. & 0.10 & 0.35 & 0.38 & 0.04 & 0.06 \\
\hline $\mathrm{MgO}$ & 3.41 & 3.17 & 6.24 & 1.46 & 0.17 & 0.07 & 0.53 & 0.78 \\
\hline $\mathrm{CaO}$ & 9.23 & 9.41 & 10.85 & 4.23 & 0.44 & 0.60 & 1.45 & 3.05 \\
\hline $\mathrm{Na}_{2} \mathrm{O}$ & 2.77 & 2.90 & 2.67 & 3.72 & 4.34 & 5.78 & 2.69 & 4.81 \\
\hline $\mathrm{K}_{2} \mathrm{O}$ & 1.23 & 1.29 & 1.80 & 7.90 & 4.08 & 4.07 & 4.06 & 1.87 \\
\hline $\mathrm{P}_{2} \mathrm{O}_{5}$ & n.d. & n.d. & n.d. & 0.19 & 0.00 & 0.03 & 0.03 & 0.10 \\
\hline $\mathrm{H}_{2} \mathrm{O}$ & $1.58-2.86^{\mathrm{a}}$ & $1.64-2.55^{\mathrm{a}}$ & $1.03-3.38^{\mathrm{a}}$ & $1.29-4.78^{b}$ & 0 & $0.72-3.57^{b}$ & 0 & $6.00-9.62^{\mathrm{a}}$ \\
\hline $\mathrm{Fe}^{2+} / \mathrm{Fe}_{\mathrm{T}}$ & $0.66-0.72^{c}$ & $0.68-0.82^{c}$ & $0.63-0.68^{c}$ & n.d. & $0.17-0.76^{c}$ & $0.44-0.64^{c}$ & $0.39-0.56^{c}$ & $0.48-0.77^{\mathrm{d}}$ \\
\hline
\end{tabular}

Notes: Oxides (in wt\%) are measured using EPMA (all Fe reported as $\mathrm{FeO}, \mathrm{FeO}_{\mathrm{T}}$ ), except $\mathrm{H}_{2} \mathrm{O}$, which is measured by aSIMS, ${ }^{\mathrm{b}} \mathrm{KFT}$, or 0 indicates assumed due to experimental conditions. $\mathrm{Fe}^{2+} / \mathrm{Fe}_{\mathrm{T}}$ is measured by ${ }^{\mathrm{w}}$ wet chemistry, ${ }^{\mathrm{d}} \mu \mathrm{XANES}$, or not determined (n.d.). ${ }^{\mathrm{e}} \mathrm{Fe}$ oxidation state measurements may have suffered from oxidation during $\mu$ XANES and are therefore not used in this study (Cottrell et al. 2018).

samples are anhydrous, low-silica glasses with a range of glass compositions: KLA-1-6-22 (Fuchs et al. 2014), SC1 (Botcharnikov et al. 2008), 140ox (Almeev et al. 2007), LS (previously unpublished studies conducted at the Institut für Mineralogie, Leibniz Universität Hannover, Germany), PF22 (Wengorsch et al. 2012), and BezBA (Almeev et al. 2013). These glass compositions were re-synthesized at various oxygen fugacities and analyzed using wet chemistry by Zhang et al. (2018), where they have been analyzed by the flank method using a moving stage approach. Hydrous, low-silica glasses are GRN (Stamper et al. 2014); ETNA (this study); MAS.1.A, MAS.1.B, and St8.1.B (Lesne et al. 2011); and AMS (Di Genova et al. 2014). GRN samples may have suffered oxidation during $\mu$ XANES (Cottrell et al. 2018), therefore their reported Fe oxidation state values are not considered further and the samples are only used to explore the effects of composition on redox changes during EPMA. The high-silica glasses range from peralkaline (FSP in Di Genova et al. 2016, and PSG in Di Genova et al. 2013) to calcalkaline (Y in Di Genova et al. 2017a, and PSB in Riker et al. 2015), with both anhydrous (FSP and Y) and hydrous (PSG and PSB) glasses.

Additional anhydrous, low-silica glasses analyzed are AII and LW (Cottrell et al. 2009), Smithsonian microbeam basaltic glass standards VG2 and VGA99 (Jarosewich et al. 1980) and PU (Ulmer 1989; Blundy et al. 2018). Compositions are given in the Supplementary Material ${ }^{1}$.

TABLE 2. Fe content and oxidation state of glasses analyzed using wavescans

\begin{tabular}{lccccc}
\hline Sample & AR10 & AR14 & AR16 & AR19 & AR20 \\
Glass composition & $1400 x$ & PF22 & $1400 x$ & LS & PF22 \\
\hline $\mathrm{FeO}_{\mathrm{T}}(\mathrm{wt} \%)$ & $9.16(24)$ & $5.75(13)$ & $7.85(13)$ & $14.79(19)$ & $4.67(12)$ \\
$\mathrm{Fe}^{2+} / \mathrm{Fe}_{\mathrm{T}}$ & $0.18(3)$ & $0.13(3)$ & $0.97(3)$ & $0.92(3)$ & $0.98(3)$ \\
\hline
\end{tabular}

Notes: Glass compositions refer to Table 1. $\mathrm{FeO}_{\mathrm{T}}$ (all Fe reported as $\mathrm{FeO}$ ) measured using EPMA and $\mathrm{Fe}^{2+} / \mathrm{Fe}_{\mathrm{T}}$ using wet chemistry. Errors of one standard deviation $(1 \sigma)$ corresponding to the last significant figure are shown in parentheses.

\section{METHODS}

\section{$\mathrm{Fe} L$ wavescans}

Wavescans of the $\mathrm{Fe} L$ peaks on glasses with varying $\mathrm{FeO}_{\mathrm{T}}$ and $\mathrm{Fe}$ oxidation state (Table 2) were analyzed to examine the controls on peak position and intensity. Data were collected on the JEOL JXA 8530F Hyperprobe at the School of Earth Sciences, University of Bristol, U.K., using a $50 \mathrm{nA}$ beam current, $10 \mu \mathrm{m}$ beam diameter, and 15 or $30 \mathrm{kV}$ accelerating voltage. Three spectrometers, with two TAP and one TAPH crystals, were moved $0.071 \mathrm{~mm}$ per step for 100 steps with $0.5 \mathrm{~s}$ dwell time over the $\mathrm{Fe} L$ peaks while the stage moved at $1 \mu \mathrm{m} / \mathrm{s}$ to minimize beam damage. To improve signal to noise ratio, multiple wavescans (40-80, depending on the accelerating voltage and glass $\mathrm{FeO}_{\mathrm{T}}$ ) were collected, and the spectra from the three spectrometers were combined to produce a single wavescan per sample.

\section{Time-dependent ratio $\mathrm{Fe} L \beta_{\mathrm{f}} / \mathrm{Fe} L \alpha_{\mathrm{f}}$ measurements}

Selecting flank positions. To identify the optimum flank positions for $\mathrm{Fe} L \beta_{\mathrm{f}} / \mathrm{Fe} L \alpha_{\mathrm{f}}$, the method of Hofer and Brey (2007) (described in the Introduction, Fig. $1 \mathrm{~b}$ ) was used. Two spectra, representing the range of $\mathrm{FeO}_{\mathrm{T}}$ and $\mathrm{Fe}$ oxidation state (AR14 and AR19, Fig. 3a), were normalized to the maximum intensity of their Fe $L \alpha$ peak from which the difference spectrum was calculated (AR14-AR19, Fig. $3 \mathrm{c}$ ). Optimum flank positions correspond to the maximum (low-wavelength flank of $\mathrm{Fe} L \alpha, \mathrm{Fe} L \alpha_{\mathrm{f}}$ ) and minimum (high-wavelength flank of $\mathrm{Fe} L \beta, \mathrm{Fe} L \beta_{\mathrm{f}}$ ) of the difference spectrum. To avoid collecting wavescans on these glasses every session, the flank positions were measured relative to the $\mathrm{F} K \alpha$ peak measured on $\mathrm{MgF}_{2}$ for each TAP/TAPH crystal. This reduced the time required to find the flank positions during future analytical sessions and minimized the area damaged by electron beam irradiation.

Electron probe setup. Each spectrometer measured a single wavelength and the spectrometer setup (referred to by crystal) was two TAP crystals to measure $\mathrm{Fe} L \alpha_{\mathrm{f}}$, TAPH for $\mathrm{Fe} L \beta_{\mathrm{f}}$, LLIF for $\mathrm{Fe} K \alpha$, and PETH for $\mathrm{K} K \alpha$. At the wavelengths of interest, the TAPH crystal offers twice the peak intensity of the TAP crystals, and the $\mathrm{Fe} L \beta$ has roughly half the intensity of the $\mathrm{Fe} L \alpha$ peak, therefore we chose the above combination of spectrometers to maximize count rates. The full-width half-maximum wavelength resolution for $\mathrm{F} K \alpha$ in $\mathrm{MgF}_{2}$ here is $0.0813,0.0835$, and $0.1034 \AA(0.8792,1.1235$, and $0.9079 \mathrm{~mm}$ spectrometer units) for the two TAP and TAPH crystals, respectively (Buse and Kearns 2018). Differential pulse height analysis (PHA) mode was used to remove interferences such as the ninth-order $\mathrm{Fe} K \alpha$, and PHA scans were collected every session on each spectrometer on $\mathrm{F} K \alpha$ 

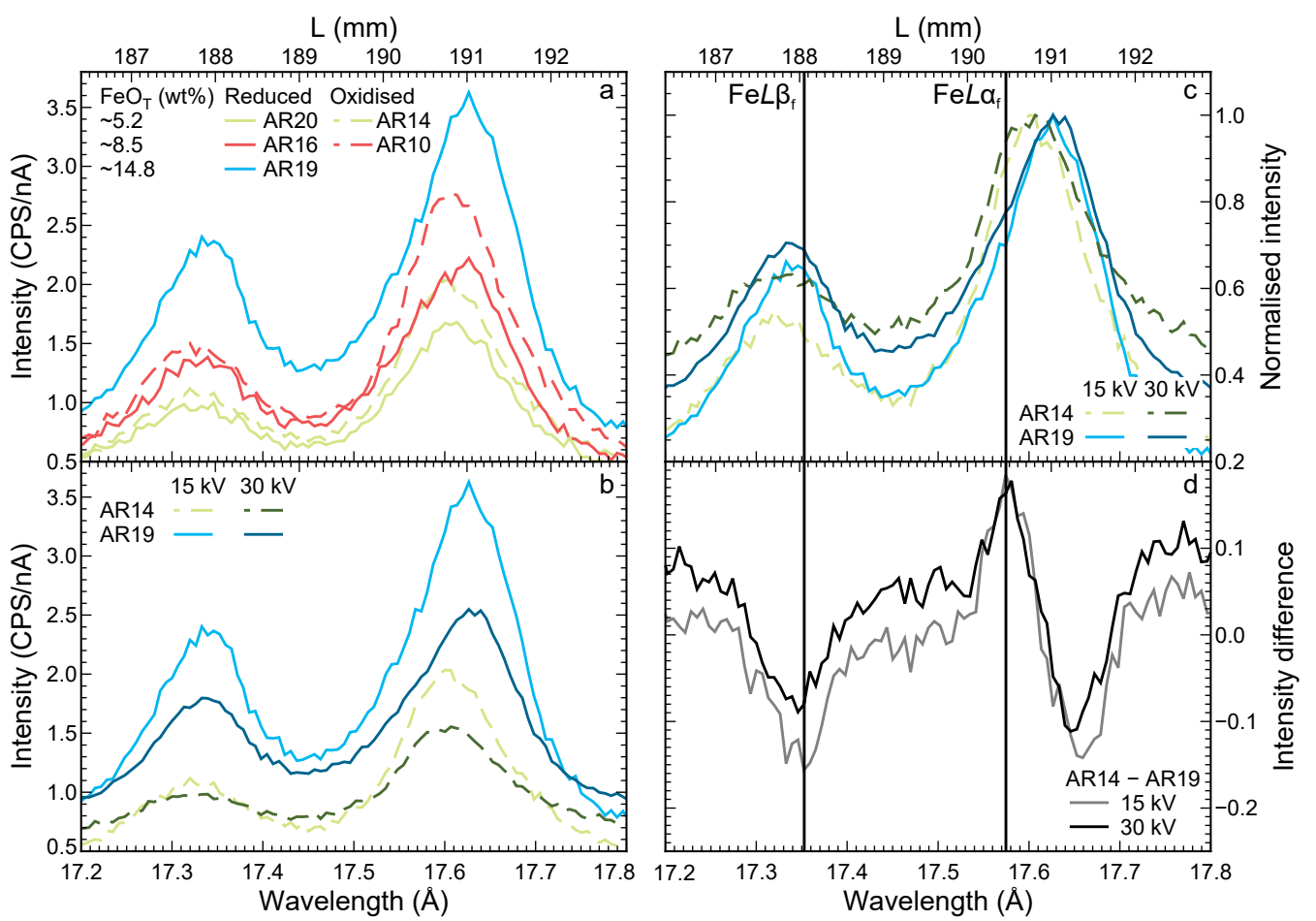

Figure 3. Wavescans of $\mathrm{Fe} L$ for silicate glasses (see Table 2 for compositions). Analytical conditions were: $50 \mathrm{nA}$ beam current and $10 \mu \mathrm{m}$ beam diameter, while the stage moved at $1 \mu \mathrm{m} / \mathrm{s}$. Spectrometer position (L) is shown along the top and equivalent wavelength along the bottom. (a) Different $\mathrm{FeO}_{\mathrm{T}}$ and $\mathrm{Fe}$ oxidation states at $15 \mathrm{kV}$ accelerating voltage, (b) different accelerating voltages, (c) different accelerating voltages with the intensity normalized to the maximum $\mathrm{Fe} L \alpha$ intensity, and (d) difference spectra (AR14-AR19) at different accelerating voltages, calculated from the normalized spectra, with optimum flank positions shown (vertical lines). The $\mathrm{Fe} L \beta_{\mathrm{f}} / \mathrm{Fe} L \alpha_{\mathrm{f}}$ ratio is 0.55 for AR14 and $0.92 \mathrm{for} \mathrm{AR} 19$ at $15 \mathrm{kV}$.

in $\mathrm{MgF}_{2}$. Na is typically the most mobile element measured during electron beam irradiation and therefore commonly used to monitor beam damage. However, in the absence of an additional TAP crystal, we measured $\mathrm{K}$ (also highly mobile) instead on a PETH crystal. For each analytical session, Fe $K \alpha$ was peaked-up on BCR-2 (USGS basaltic glass standard), KKa on sanidine, and the peak position of $\mathrm{FK} \alpha$ was measured on $\mathrm{MgF}_{2}$ to calculate the wavelengths of the flank positions on each TAP/TAPH crystal. Spectrometers were static during analysis as backgrounds are not required for flank analyses (Hofer et al. 1994). As no other elements (or backgrounds) were measured, no matrix correction could be performed to quantify $\mathrm{Fe}$ or $\mathrm{K}$, thus only their relative intensity over time is used. Analytical conditions were a $15 \mathrm{kV}$ accelerating voltage, $50 \mathrm{nA}$ beam current, and 4-15 $\mu \mathrm{m}$ beam diameter, which allows the analysis of small volumes of glass. Intensity measurements were collected over $5 \mathrm{~s}$ for a total duration of $\sim 150 \mathrm{~s}$ on the same spot of glass. Ten repeat analyses on fresh glass per sample were collected, resulting in a total analysis area of $\sim 20-60 \mu \mathrm{m}$ diameter. Data were collected over five sessions. A summary of the analytical protocol is provided in the Supplementary Material ${ }^{1}$.

Redox stability. To investigate the effect of analytical conditions on redox changes, additional measurements were made at different analytical conditions

TABLE 3. EPMA conditions for time-dependent ratio $\mathrm{Fe} L \beta_{\mathrm{f}} / \mathrm{Fe} L \mathrm{a}_{\mathrm{f}}$ measurements

\begin{tabular}{lcccccc}
\hline Condition & $\begin{array}{c}\text { Accelerating } \\
\text { voltage }(\mathrm{kV})\end{array}$ & $\begin{array}{c}\text { Beam current } \\
(\mathrm{nA})\end{array}$ & $\begin{array}{c}\text { Beam } \\
\text { diameter }(\mu \mathrm{m})\end{array}$ & $\begin{array}{c}\text { Number of } \\
\text { analyses }\end{array}$ & $\begin{array}{c}\text { Total } \\
\text { duration }(\mathrm{s})\end{array}$ \\
\hline 1 & 15 & 50 & 4 & 10 & 150 \\
2 & 15 & 50 & 10 & 10 & 150 \\
3 & 15 & 50 & 15 & 10 & 150 \\
4 & 15 & 50 & 20 & 10 & 150 \\
5 & 15 & 500 & 10 & 1 & 360 \\
6 & 30 & 50 & 10 & 10 & 150 \\
\hline
\end{tabular}

Notes: Conditions 1-3 were used to quantify Fe oxidation state, and additional measurements were made at conditions 4-6 on AR10, AR16, MAS.1.B4, and PSB63 to investigate redox stability.
(Table 3) on four glasses chosen to represent the range of glass compositions studied (Table 4). AR10 and AR16 are anhydrous low-silica glasses, which are oxidized and reduced, respectively. MAS.1.B4 and PSB63 are hydrous glasses that are low- and high-silica, respectively.

Data processing. To check for sample homogeneity, $\mathrm{Fe} K \alpha$ was compared between repeat analyses. If the $\mathrm{Fe} K \alpha$ intensity was significantly outside the counting error for other repeats, the erroneous repeat analysis was removed from further processing and, if the sample was too inhomogeneous, the sample was not processed further. The analyses were then averaged at each time interval for $\mathrm{Fe} L \alpha_{\mathrm{f}}$ (separately for each spectrometer), $\mathrm{Fe} L \beta_{\mathrm{f}}, \mathrm{Fe} K \alpha$, and $\mathrm{K} K \alpha$. Using these averages at each time interval, $\mathrm{Fe} L \beta_{\mathrm{f}}$ was divided by the sum of $\mathrm{Fe} L \alpha_{\mathrm{f}}$ from the two spectrometers to calculate $\mathrm{Fe} L \beta_{\mathrm{f}} / \mathrm{Fe} L \alpha_{\mathrm{f}}$. Errors on $\mathrm{Fe} K \alpha, \mathrm{K} K \alpha, \mathrm{Fe} L \beta_{\mathrm{f}} / \mathrm{Fe} L \alpha_{\mathrm{f}}$ and time are the standard deviation of the repeat measurements. An exponential equation of the following form was fitted to each sample:

TABLE 4. Glass compositions of AR10, AR16, MAS.1.B4, and PSB63

\begin{tabular}{lcccc}
\hline & AR10 & AR16 & MAS.1.B4 & PSB63 \\
\hline $\mathrm{SiO}_{2}$ & $49.91(30)$ & $50.46(27)$ & $49.72(22)$ & $64.21(32)$ \\
$\mathrm{TiO}_{2}$ & $0.97(2)$ & $1.00(2)$ & $1.16(3)$ & $0.33(2)$ \\
$\mathrm{Al}_{2} \mathrm{O}_{3}$ & $15.67(1)$ & $16.08(3)$ & $18.60(5)$ & $14.81(18)$ \\
$\mathrm{FeO}$ & $9.16(24)$ & $7.85(13)$ & $10.88(9)$ & $3.26(8)$ \\
$\mathrm{MnO}$ & $0.17(1)$ & $0.18(1)$ & $0.03(1)$ & $0.07(6)$ \\
$\mathrm{MgO}$ & $9.49(2)$ & $10.38(5)$ & $3.28(3)$ & $0.75(6)$ \\
$\mathrm{CaO}$ & $11.89(10)$ & $12.53(5)$ & $8.89(7)$ & $2.91(6)$ \\
$\mathrm{Na}$ & $2.20(2)$ & $1.93(3)$ & $2.89(4)$ & $4.35(28)$ \\
$\mathrm{K}_{2} \mathrm{O}$ & $0.06(1)$ & $0.06(1)$ & $1.25(1)$ & $1.70(12)$ \\
$\mathrm{P}_{2} \mathrm{O}_{5}$ & $0.08(1)$ & $0.09(1)$ & $0.03(1)$ & $0.10(5)$ \\
$\mathrm{H}_{2} \mathrm{O}$ & 0 & 0 & $2.55(13)$ & $7.11(16)$ \\
$\mathrm{Fe}^{2+} / \mathrm{Fe}_{\mathrm{T}}$ & $0.18(3)^{\mathrm{a}}$ & $0.97(3)^{\mathrm{a}}$ & $0.82(3)^{\mathrm{a}}$ & $0.76(2)^{\mathrm{b}}$ \\
\hline
\end{tabular}

Notes: Oxides (in wt\%) are measured using EPMA (all Fe reported as FeO, FeO except $\mathrm{H}_{2} \mathrm{O}$, which is measured by SIMS or 0 indicates assumed due to experimental conditions. $\mathrm{Fe}^{2+} / \mathrm{Fe}_{\mathrm{T}}$ is measured by a wet chemistry or ${ }^{\mathrm{b}} \mu \mathrm{XANES}$. Errors of $1 \sigma$ corresponding to the last significant figure are shown in parentheses. 


$$
I=\left(I_{0}-I_{\infty}\right) \exp \left(\frac{I_{0}^{\prime} t}{I_{0}-I_{\infty}}\right)+I_{\infty}
$$

where $I$ is the $\mathrm{Fe} L \beta_{\mathrm{f}} / \mathrm{Fe} L \alpha_{\mathrm{f}}$ intensity ratio and $t$ is time, subscripts refer to the values at $t=0$ and $\infty$, and $I_{0}^{\prime}$ is the rate of change of $I$ with time at $t=0$. When the minimization failed to converge, $I_{\infty}$ was fixed to the last measured value for the sample. The error in both these cases is the standard error on the fit coefficients. In those cases where $\mathrm{Fe} L \beta_{\mathrm{f}} / \mathrm{Fe} L \alpha_{\mathrm{f}}$ was constant with time, convergence is not possible, therefore the average of $\mathrm{Fe} L \beta_{\mathrm{f}} / \mathrm{Fe} L \alpha_{\mathrm{f}}$ with time was used, where the error was the standard deviation of these data. Analyses with large errors $\left(> \pm 0.1\right.$ for $I_{0}$ and $> \pm 0.01$ for $I_{0}^{\prime}$ ), likely due to inhomogeneity, extremely rapid redox changes or analytical problems, are discarded. An R code for data processing is included in the Supplementary Material ${ }^{1}$.

\section{Raman spectroscopy}

Raman spectroscopy was used to detect the presence of nanolites before and after electron beam irradiation as nanolites alter the Raman spectra of silicate glasses. Magnetite nanolites produce a peak at $\sim 670 \mathrm{~cm}^{-1}$, which also decreases the intensity of the surrounding silicate peaks (Di Genova et al. 2017a, 2017b). Carbon coats were removed prior to analysis. Raman spectra were collected using the Thermo-Scientific DXRxi Raman Imaging Microscope at the School of Earth Sciences, University of Bristol, U.K., with a green (520 nm) laser, 50× (long distance) or $100 \times$ objective, and $3-5 \mathrm{~mW}$ power to avoid sample oxidation. An extended grating was used to also collect data on $\mathrm{H}_{2} \mathrm{O}$ content. All samples, except AMS, FSP, PSG, and Y, which have been previously analyzed by Di Genova et al. (2017a, 2017b), were analyzed on non-irradiated areas of glass. Selected glasses that cover a range of compositions (ETNA08, MAS.1.A5, FSP1, FSP9, PSG6, and PSB63) were additionally analyzed following electron beam irradiation.

\section{RESULTS}

\section{Electron probe microanalysis}

Wavelength and intensity changes of $\mathrm{Fe} L$ lines in silicate glasses. For the same Fe oxidation state, peak intensity increases and peak positions shift to higher wavelengths with increasing $\mathrm{FeO}_{\mathrm{T}}$ (Fig. 3a). For the same $\mathrm{FeO}_{\mathrm{T}}$ oxidized samples have greater peak intensities and lower wavelength peak positions than reduced samples (Fig. 3a). At higher accelerating voltages (30 vs. $15 \mathrm{kV}$ ) the intensity of $\mathrm{Fe} L \alpha$ and $\mathrm{Fe} L \beta$ decrease, but there is no appreciable shift in peak positions (Fig. 3b). Therefore, there is no appreciable change in optimum flank positions, although the difference between the flank intensities decreases (Fig. 3c).

Time-dependent intensity changes during electron beam irradiation. During electron beam irradiation, the intensity of $\mathrm{K} K \alpha$ remains stable (anhydrous glasses) or decreases (hydrous glasses) over time (Fig. 4), whereas for Fe $K \alpha$ the intensity remains stable (anhydrous glasses) or increases (hydrous glasses)

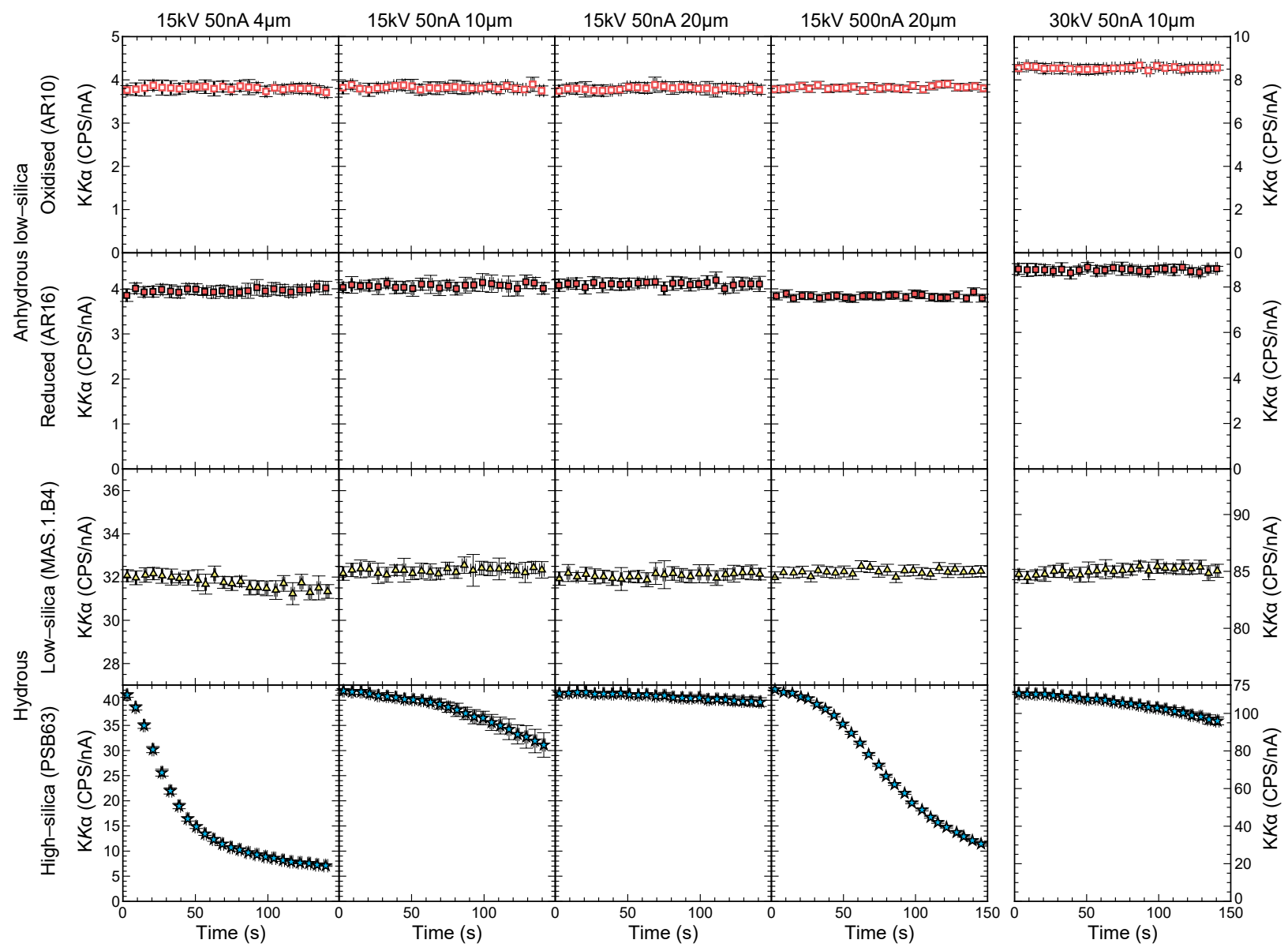

FIGURE 4. Intensity of KKa with time. Analytical conditions (accelerating voltage, beam current, and beam diameter) shown along the top and sample description on the left-hand side. Symbols and colors as Figure 2a except that open/closed symbol indicates initial Fe oxidation state: open symbols are oxidized $\left(\mathrm{Fe}^{2+} / \mathrm{Fe}_{\mathrm{T}}<0.2\right)$; closed symbols are reduced $\left(\mathrm{Fe}^{2+} / \mathrm{Fe}_{\mathrm{T}}>0.7\right)$. 


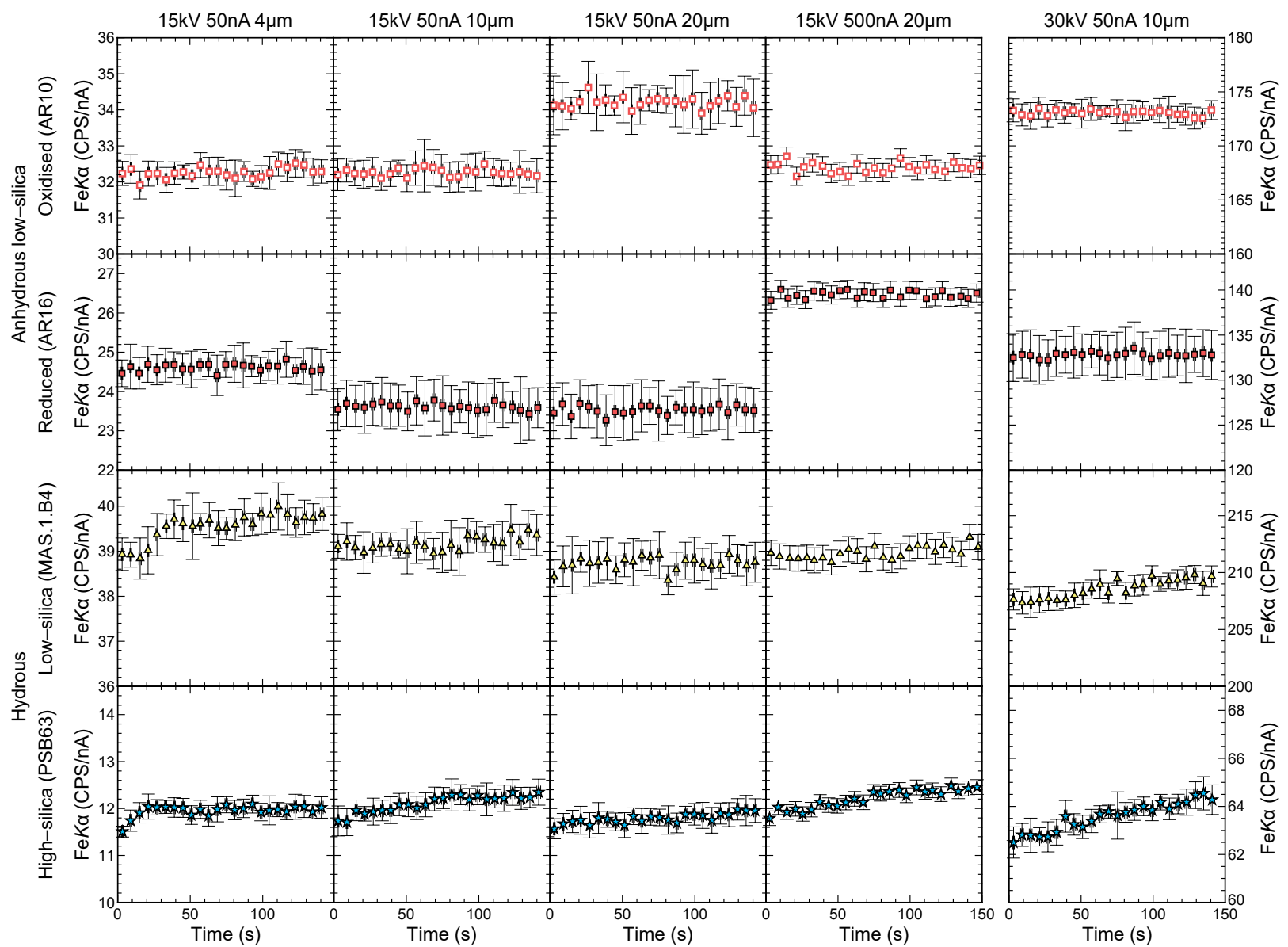

FIGURE 5. Intensity of Fe $K \alpha$ with time. Analytical conditions (accelerating voltage, beam current, and beam diameter) shown along the top and sample description on the left-hand side. Symbols and colors as Figure 4.

(Fig. 5). The ratio of $\mathrm{Fe} L \beta_{\mathrm{f}} / \mathrm{Fe} L \alpha_{\mathrm{f}}$ increases (anhydrous lowsilica), remains stable (anhydrous low-silica and hydrous highsilica), or decreases (hydrous low-silica) over time (Fig. 6). In those cases where intensity changes are observed, the rate typically increases with decreasing beam diameter, decreasing accelerating voltage, and increasing beam current. Data were collected during different sessions, therefore differences in the absolute intensity at different conditions are not meaningful.

\section{Raman spectroscopy}

Before electron beam irradiation. The majority of glasses analyzed are nanolite-free prior to electron beam irradiation (Figs. 7a and 7b). Exceptions are AR37 (composition LS) and ETNA(2) (samples ETNA 3, 6, 7, 8, 14, 16, and 30), with a peak at $\sim 670 \mathrm{~cm}^{-1}$ indicating magnetite nanolites. Magnetite nanolites were detected in AMS4 and Y-L using Raman spectroscopy by Di Genova et al. (2017a, 2017b).

After electron beam irradiation. Most glasses analyzed following electron beam irradiation (MAS.1.A4, FSP1, FSP9, and PSG6) exhibit new magnetite nanolites (peak at $\sim 670 \mathrm{~cm}^{-1}$ wavenumbers) when irradiated using a $4 \mu \mathrm{m}$ beam diameter implying oxidation (Fig. 7c). Additionally, ETNA08, MAS.1.A4, and PSG6 have a new peak at $\sim 1350 \mathrm{~cm}^{-1}$, which corresponds to hematite (RUFF Raman spectra database, http://rruff.info/, Lafuente et al. 2015), implying the formation of hematite nanolites following electron beam irradiation (Fig. 7c). PSB63 shows no evidence for the presence of Fe-bearing nanolites following electron beam irradiation. The $\mathrm{H}_{2} \mathrm{O}$ peak $\left(\sim 3600 \mathrm{~cm}^{-1}\right)$ shows a decrease in height after electron beam irradiation for hydrous samples (ETNA08, MAS.1.A4, PSG6, and PSB63), implying a loss of water.

\section{CONTROLS ON FE REDOX CHANGES IN SILICATE GLASSES DURING ELECTRON BEAM IRRADIATION}

The ratio of $\mathrm{Fe} L \beta_{\mathrm{f}} / \mathrm{Fe} L \alpha_{\mathrm{f}}$ over time increased, remained stable, or decreased (Fig. 6), which could be due to various causes as $\mathrm{Fe} L \beta_{\mathrm{f}} / \mathrm{Fe} L \alpha_{\mathrm{f}}$ depends on Fe concentration, oxidation state, and coordination. Fe $K \alpha$ increases over time (Fig. 5), implying an increase in $\mathrm{Fe}_{\mathrm{T}}$. This is due to the process of "grow-in" (Morgan and London 2005), where the concentration of immobile elements (e.g., $\mathrm{Si}, \mathrm{Al}$, and $\mathrm{Fe}$ ) increases due to the migration of alkalis (e.g., $\mathrm{Na}^{+}$and $\mathrm{K}^{+}$, Fig. 4) and $\mathrm{H}^{+}$(Fig. 7c) toward the buildup of negative charge at depth (e.g., Humphreys et al. 2006) and possible density changes. The increase in $\mathrm{Fe}_{\mathrm{T}}$ implied by the increase in $\mathrm{Fe} K \alpha$ for hydrous silicate glasses (MAS.1.B4 and PSB63, Fig. 5) is small $\left(\sim 0.13 \mathrm{wt} \% \mathrm{FeO}_{\mathrm{T}}\right)$. This is calculated to 


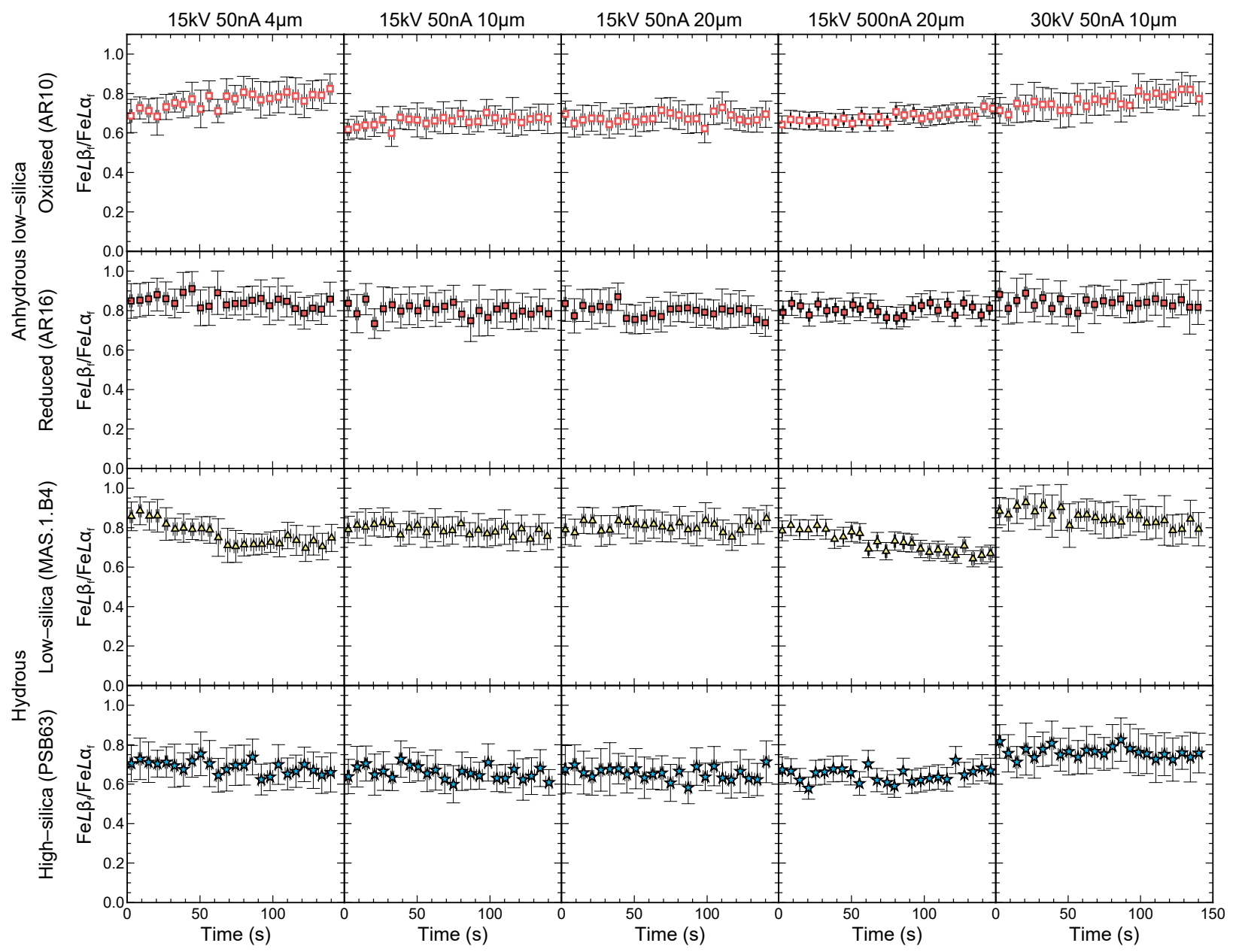

FIGURE 6. Intensity ratio of $\mathrm{Fe} L \beta_{\mathrm{f}} / \mathrm{Fe} L \alpha_{\mathrm{f}}$ with time. Analytical conditions (accelerating voltage, beam current, and beam diameter) shown along the top and sample description on the left-hand side. Symbols and colors as Figure 4.

cause a negligible change on $\mathrm{Fe} L \beta_{\mathrm{f}} / \mathrm{Fe} L \alpha_{\mathrm{f}}(\sim 0.004$, within measurement error), and therefore changes due to Fe concentration are not considered further.

Additional carbon contamination can be deposited on the sample during electron beam irradiation (Bastin and Heijligers 1988). This can change X-ray intensities over time due to the reduction of the electron landing energy caused by energy loss within and X-ray absorption by the contaminant (Reed 1975). The former is negligible at the high voltages used here, whereas the latter should not affect $\mathrm{Fe} L \beta_{\mathrm{f}} / \mathrm{Fe} L \alpha_{\mathrm{f}}$ as the mass absorption coefficients of $\mathrm{Fe} L \alpha$ and $\mathrm{Fe} L \beta$ by $\mathrm{C}$ are very similar (5762.34 and $5485.53 \mathrm{~cm}^{2} / \mathrm{g}$, respectively, from the FFAST database). To change $\mathrm{Fe} L \beta_{\mathrm{f}} / \mathrm{Fe} L \alpha_{\mathrm{f}}$ by $1 \%$ relative (within measurement error) would require $>100 \mathrm{~nm}$ of $\mathrm{C}$ contamination (calculated using CalcZAF) during the $150 \mathrm{~s}$ analysis. This is far more than has been measured in previous studies (e.g., $8 \pm 2 \mathrm{~nm}$ over $180 \mathrm{~s}$; Buse et al. 2016), therefore the effect of contamination can be considered negligible.

These considerations imply that any changes observed in $\mathrm{Fe} L \beta_{\mathrm{f}} / \mathrm{Fe} L \alpha_{\mathrm{f}}$ are due primarily to changes in Fe oxidation state over time. Increasing $\mathrm{Fe} L \beta_{\mathrm{f}} / \mathrm{Fe} L \alpha_{\mathrm{f}}$ is caused by increasing
$\mathrm{Fe}^{2+} / \mathrm{Fe}_{\mathrm{T}}$ and hence $\mathrm{Fe}$ reduction $\left(\mathrm{Fe}^{3+} \rightarrow \mathrm{Fe}^{2+}\right)$. Conversely, decreasing $\mathrm{Fe} L \beta_{\mathrm{f}} / \mathrm{Fe} L \alpha_{\mathrm{f}}$ is caused by decreasing $\mathrm{Fe}^{2+} / \mathrm{Fe}_{\mathrm{T}}$ and hence Fe oxidation $\left(\mathrm{Fe}^{2+} \rightarrow \mathrm{Fe}^{3+}\right)$. Finally, no change in $\mathrm{Fe} L \beta_{\mathrm{f}} / \mathrm{Fe} L \alpha_{\mathrm{f}}$ with time implies stable $\mathrm{Fe}^{2+} / \mathrm{Fe}_{\mathrm{T}}$ during analysis. The presence of predominantly magnetite nanolites after electron beam irradiation implies that oxidation proceeds via precipitation of $\mathrm{FeO} \cdot \mathrm{Fe}_{2} \mathrm{O}_{3}$, not just $\mathrm{Fe}_{2} \mathrm{O}_{3}$, as has been previously suggested (Fialin and Wagner 2012).

\section{Direction of redox change: Total mobile cations}

To investigate the compositional controls on the rate and mechanism of redox changes during electron beam irradiation, we define the parameter Total Mobile Cations (TMC), which is the molar sum of $\left(\mathrm{H}_{2} \mathrm{O}+\mathrm{Na}_{2} \mathrm{O}+\mathrm{K}_{2} \mathrm{O}\right)$ per gram of glass (units: $\mathrm{mol} / \mathrm{g}$ ). This provides a maximum estimate of the moles of available oxygen if all the $\mathrm{H}^{+}, \mathrm{Na}^{+}$, and $\mathrm{K}^{+}$migrated due to the buildup of negative charge (Humphreys et al. 2006). TMC is typically dominated by $\mathrm{H}_{2} \mathrm{O}$ due to the low atomic mass of $\mathrm{H}$ compared to $\mathrm{Na}$ and K. Figure 8 shows the rate of change of $\mathrm{Fe} L \beta_{\mathrm{f}} / \mathrm{Fe} L \alpha_{\mathrm{f}}$ with time at time zero $\left(I_{0}^{\prime}\right)$ against TMC. Glasses with TMC $<0.1$ $\mathrm{mol} / \mathrm{g}$ remain stable or reduce over time $\left(I_{0}^{\prime} \geq 0 \mathrm{~s}^{-1}\right)$, correspond- 

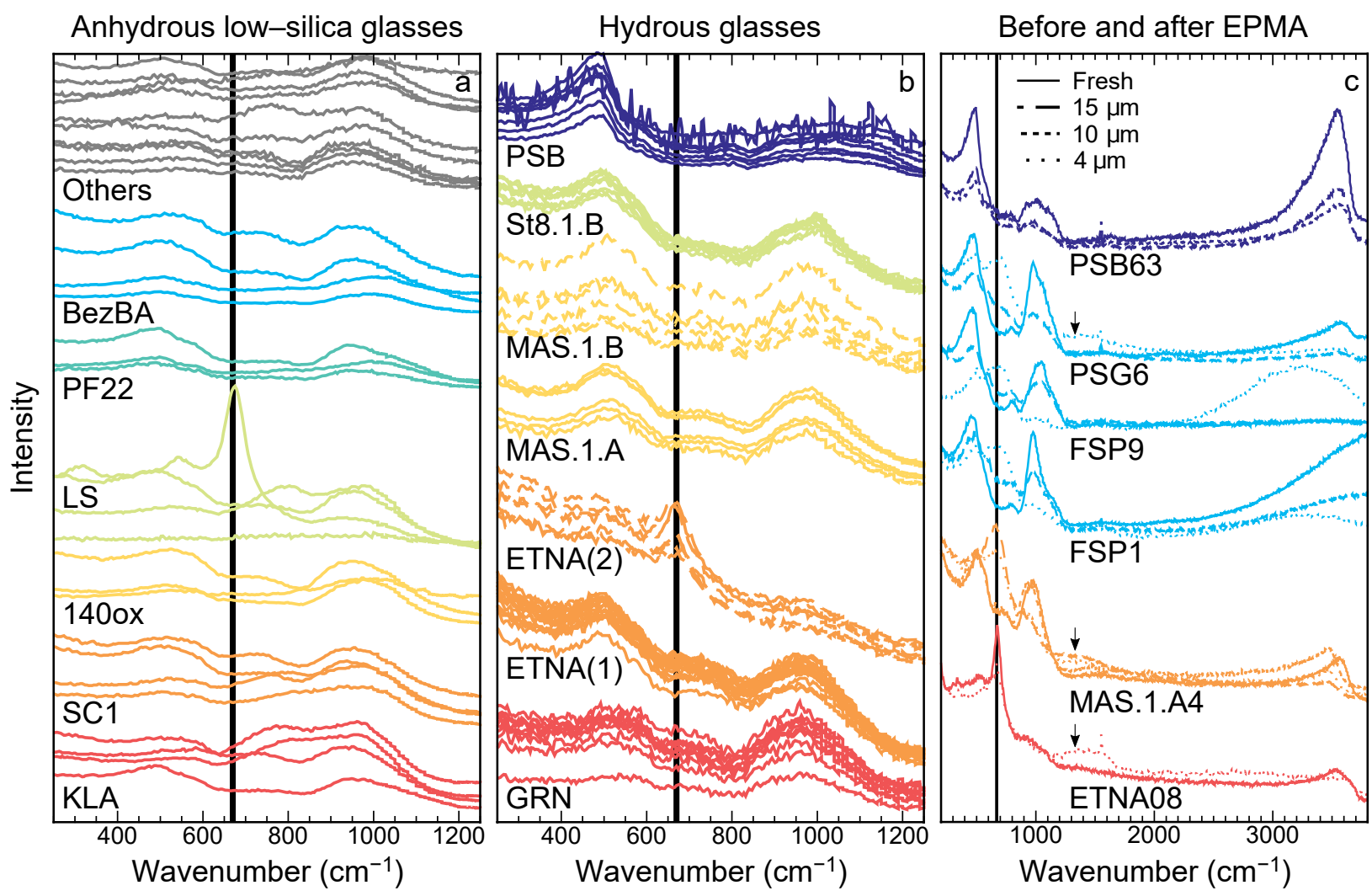

FIGURE 7. Raman spectra (one spectrum is shown for each sample) for (a) anhydrous low-silica and (b) hydrous glasses, where spectra are grouped, colored, and offset vertically by average glass composition (labeled under the group of spectra), and intensity is in arbitrary units, and (c) selected glasses before and after electron beam irradiation at a $15 \mathrm{kV}$ accelerating voltage, $50 \mathrm{nA}$ beam current, and beam diameter indicated by line style. Black, dashed vertical lines indicate the wavenumber of magnetite, and arrows indicate the wavenumber of hematite.

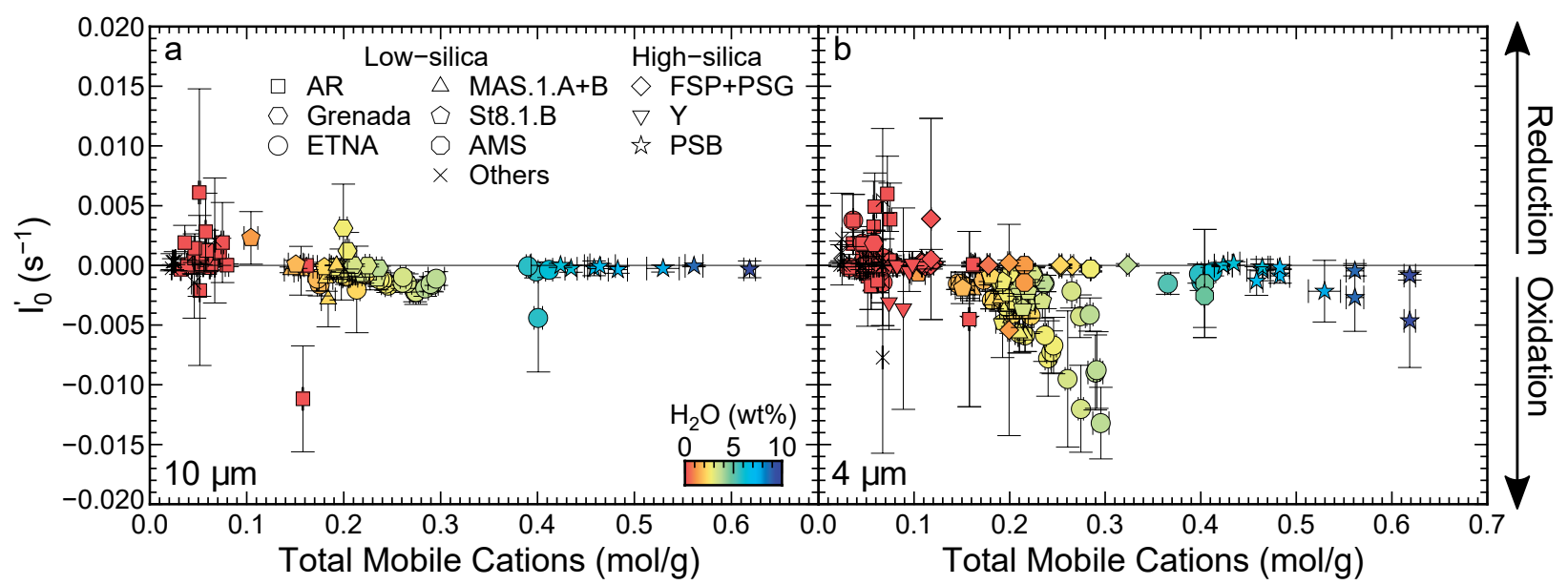

Figure 8. The rate of change of $\mathrm{Fe} L \beta_{\mathrm{f}} / \mathrm{Fe} L \alpha_{\mathrm{f}}$ with time at time zero $\left(I_{0}^{\prime}\right)$ against Total Mobile Cations $\left(\mathrm{TMC}, \mathrm{molar}\right.$ sum of $\mathrm{H}_{2} \mathrm{O}+\mathrm{Na}_{2} \mathrm{O}+\mathrm{K}_{2} \mathrm{O}$ per gram of glass), where symbol shape indicates average glass composition (Table 1) and color indicates $\mathrm{H}_{2} \mathrm{O}$. Analytical conditions were: $15 \mathrm{kV}$ accelerating voltage, $50 \mathrm{nA}$ beam current, and (a) 10 and (b) $4 \mu \mathrm{m}$ beam diameter. 


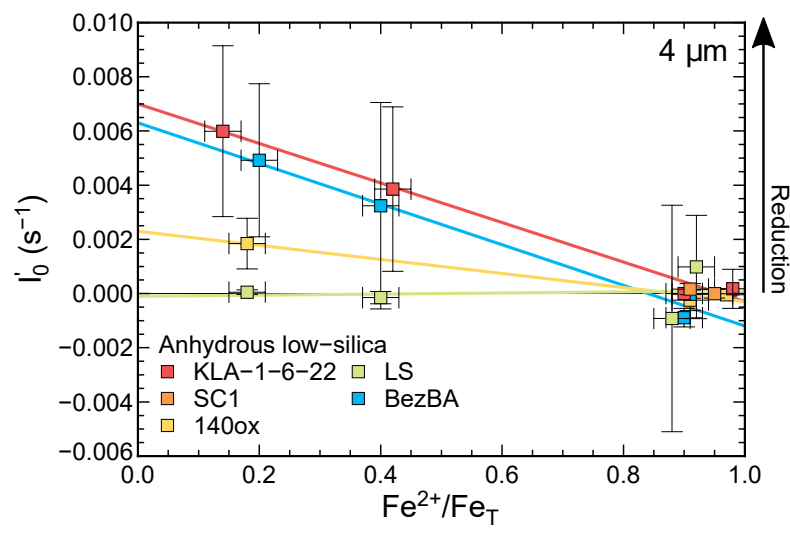

FIGURE 9. The rate of change of $\mathrm{Fe} L \beta_{\mathrm{f}} / \mathrm{Fe} L \alpha_{\mathrm{f}}$ with time at time zero $\left(I_{0}^{\prime}\right)$ against $\mathrm{Fe}^{2+} / \mathrm{Fe}_{\mathrm{T}}$ for anhydrous low-silica glasses, where symbol color indicates average glass composition (Table 1) and linear regressions are shown (solid lines). Analytical conditions were: $15 \mathrm{kV}$ accelerating voltage, $50 \mathrm{nA}$ beam current, and $4 \mu \mathrm{m}$ beam diameter.

ing to anhydrous $\left(\mathrm{H}_{2} \mathrm{O}<0.38 \mathrm{wt} \%\right)$, alkali-poor $\left(\mathrm{Na}_{2} \mathrm{O}+\mathrm{K}_{2} \mathrm{O}\right.$ $<5.5 \mathrm{wt} \%$ ) glasses. Conversely, glasses with TMC $>0.1 \mathrm{~mol} / \mathrm{g}$ remain stable or oxidize over time $\left(I_{0}^{\prime} \geq 0 \mathrm{~s}^{-1}\right)$ corresponding to either hydrous $\left(\mathrm{H}_{2} \mathrm{O}>1.03 \mathrm{wt} \%\right)$ or alkali-rich $(11.3 \pm 0.2 \mathrm{wt} \%$ $\mathrm{N}_{2} \mathrm{O}+\mathrm{K}_{2} \mathrm{O}$ ) glasses. The mechanisms causing reduction are likely always to occur in the glass during electron beam irradiation, therefore it appears that at $\mathrm{TMC} \geq 0.1 \mathrm{~mol} / \mathrm{g}$ the rate of oxidation is greater than the rate of reduction, hence oxidation prevails.

\section{Rate of reduction: Initial Fe oxidation state}

Figure 9 shows $I_{0}^{\prime}$ against initial $\mathrm{Fe}^{2+} / \mathrm{Fe}_{\mathrm{T}}$ for anhydrous, lowsilica (43-56 wt $\% \mathrm{SiO}_{2}$ ) glasses where, for a specific glass composition, $\mathrm{Fe}^{2+} / \mathrm{Fe}_{\mathrm{T}}$ correlates negatively with rate of reduction. Glasses that are mostly reduced $\left(\mathrm{Fe}^{2+} / \mathrm{Fe}_{\mathrm{T}}>0.9\right)$ cannot reduce any further and remain stable, therefore reduction is confined to initially oxidized glasses. Between the suites of glass with different compositions, there is no obvious compositional control on $I_{0}^{\prime}$.

\section{Rate of oxidation}

$\mathbf{H}_{2} \mathrm{O}$ content. Figure 10 shows the rate of change of $\mathrm{Fe} L \beta_{\mathrm{f}} / \mathrm{Fe} L \alpha_{\mathrm{f}}$ over time at time zero $\left(I_{0}^{\prime}\right)$ against TMC for suites of low-silica glasses $\left(43-56 \mathrm{wt} \% \mathrm{SiO}_{2}\right)$ that have variable $\mathrm{H}_{2} \mathrm{O}$ concentrations, but constant glass composition. Broadly, $I_{0}^{\prime}$ becomes more negative with increasing TMC. For a fixed glass composition the increase in TMC is due to increasing $\mathrm{H}_{2} \mathrm{O}$ content, therefore the rate of oxidation increases with increasing $\mathrm{H}_{2} \mathrm{O}$. The diffusivity of $\mathrm{H}_{2} \mathrm{O}$ in basaltic glasses depends on the total $\mathrm{H}_{2} \mathrm{O}$ content (Okumura and Nakashima 2006), thus the rate of oxidation increases with increasing $\mathrm{H}_{2} \mathrm{O}$ diffusivity. These results show that the migration of $\mathrm{H}^{+}$, in addition to $\mathrm{Na}^{+}$and $\mathrm{K}^{+}$as previously suggested by Fialin and Wagner (2012), leads to oxidation of Fe during electron beam irradiation. In fact, when considering the mobile cation responsible for $\mathrm{Fe}$ oxidation, $\mathrm{H}^{+}$plays a more important role than might be expected from its oxide $\mathrm{wt} \%$ concentrations alone due to the low atomic mass of $\mathrm{H}$.

$\mathrm{SiO}_{2}$ content. High-silica $\left(61-78 \mathrm{wt} \% \mathrm{SiO}_{2}\right)$ glasses remain broadly stable during electron beam irradiation (Fig. 8), despite the Raman spectra of electron beam irradiated areas using a $4 \mu \mathrm{m}$ beam diameter indicating the formation of magnetite nanolites (Fig. 7c). This implies extremely rapid oxidation at $4 \mu \mathrm{m}$, which is consistent with the rate of alkali migration, and probably $\mathrm{H}$, being faster during electron beam irradiation of high-silica compared to low-silica glasses (e.g., Fig. 4; Hayward 2011). This may be due to the more polymerized structure of high-silica glasses (Mysen et al. 1982).

Fe content. PSB glasses do not oxidize $\left(I_{0}^{\prime} \approx 0 \mathrm{~s}^{-1}\right.$, Fig. 8$)$, and there are no Fe-bearing nanolites observable in the Raman spectra prior to or following electron beam irradiation (Fig. 7c), despite $\mathrm{TMC}>0.4 \mathrm{~mol} / \mathrm{g}$ due to their high alkali and water contents. These glasses contain little $\mathrm{Fe}\left(\mathrm{FeO}_{\mathrm{T}} \leq 3.2 \mathrm{wt} \%\right)$, which could hinder oxidation as $\mathrm{FeO}$ groups may need to lie close together to produce $\mathrm{Fe}_{2} \mathrm{O}_{3}$.

Presence of nanolites. Surprisingly, low-silica (47-58 wt\% $\mathrm{SiO}_{2}$ ) glasses with TMC $>0.35 \mathrm{~mol} / \mathrm{g}$, which corresponds to $\mathrm{H}_{2} \mathrm{O}>4 \mathrm{wt} \%$ (Fig. 10), appear stable $\left(I_{0}^{\prime} \approx 0 \mathrm{~s}^{-1}\right)$. It is possible that they oxidized very quickly and the change is not observable. Analyses using a $10 \mu \mathrm{m}$ beam size are also stable (Fig. 8a), but there is evidence for the formation of hematite nanolites during electron beam irradiation (Fig. 7c). This either means the oxidation is extremely rapid, due to the very high $\mathrm{H}_{2} \mathrm{O}$ contents, or not occurring due to the presence of magnetite nanolites before irradiation where the Fe may be stable, but further study is required to understand this process fully.

\section{Effect of analytical conditions}

For all X-rays measured $\left(K K \alpha, \mathrm{Fe} K \alpha\right.$, and $\left.\mathrm{Fe} L \beta_{\mathrm{f}} / \mathrm{Fe} L \alpha_{\mathrm{f}}\right)$, the rate of change of intensity increases with decreasing beam diameter, decreasing accelerating voltage, and increasing beam current (Figs. 4, 5, 6, and 8), as is commonly observed during electron beam irradiation (e.g., Morgan and London 2005). The analytical conditions control the electron density implanted into the sample and, therefore, the magnitude of sub-surface charging. Increasing the beam current increases the electron dosage to the sample. The interaction volume is reduced by decreasing

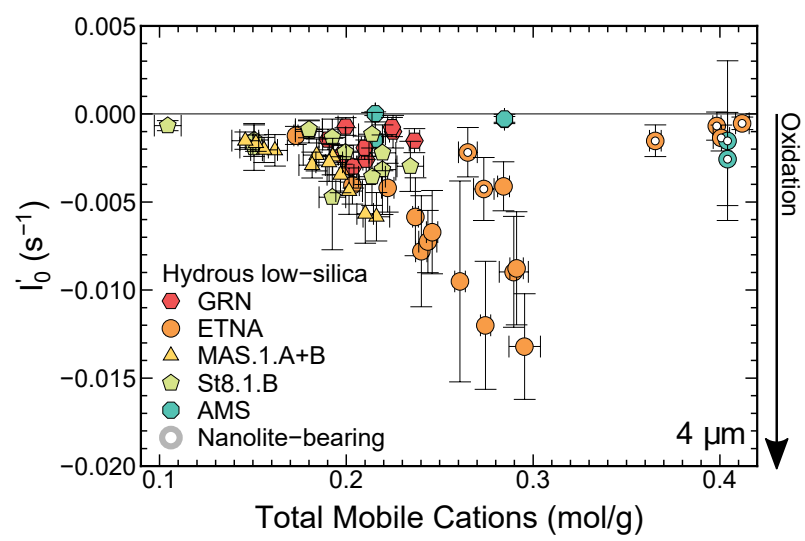

FIGURE 10. The rate of change of $\mathrm{Fe} L \beta_{\mathrm{f}} / \mathrm{Fe} L \alpha_{\mathrm{f}}$ with time at time zero $\left(I_{0}^{\prime}\right)$ against Total Mobile Cations (TMC) for hydrous low-silica glasses, where symbol shape and color indicates average glass composition (Table 1), and open symbols indicate the presence of nanolites. Analytical conditions were: $15 \mathrm{kV}$ accelerating voltage, $50 \mathrm{nA}$ beam current, and $4 \mu \mathrm{m}$ beam diameter. 


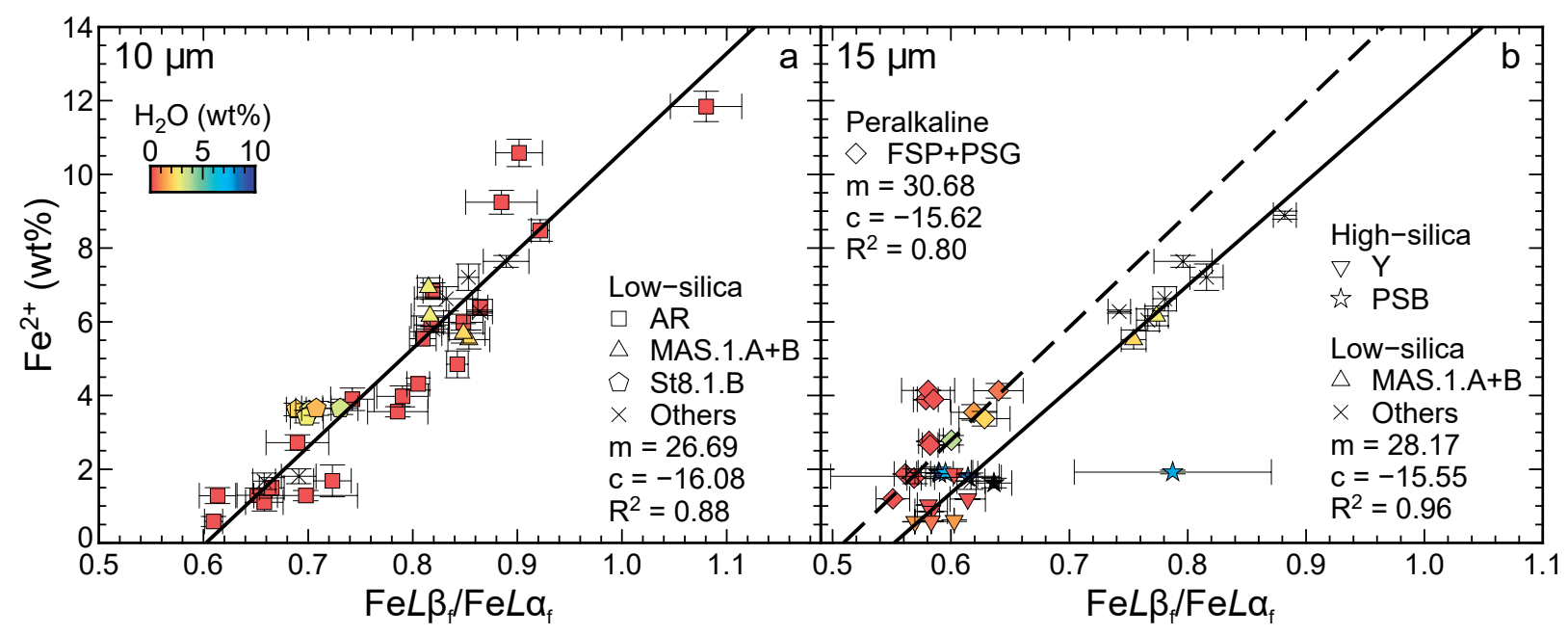

FIGURE 11. Calibration curves derived for two sessions ( 1 and 5), where $\mathrm{Fe}^{2+}$ is constrained using $\mathrm{Fe}^{2+} / \mathrm{Fe}_{\mathrm{T}}$ from independent techniques and $\mathrm{Fe}$ from EPMA. Symbol shape indicates average glass composition (Table 1) and color indicates $\mathrm{H}_{2} \mathrm{O}$. Analytical conditions were: $15 \mathrm{kV}$ accelerating voltage and $50 \mathrm{nA}$ beam current. (a) Low-silica glasses using $10 \mu \mathrm{m}$ beam diameter, and (b) all glasses with separate calibration curves for lowsilica (solid) and peralkaline (dashed) glasses (high-silica glasses are shown but not included in the fit), using a $15 \mu \mathrm{m}$ beam diameter.

TABLE 5. Example of results for weighted linear regression for $\mathrm{Fe}^{2+}$ calibration

\begin{tabular}{lcccccc}
\hline No. & $\begin{array}{c}\text { Beam } \\
\text { diameter }(\mu \mathrm{m})\end{array}$ & $\mathrm{n}$ & $m$ & $c$ & $\begin{array}{c}\text { Adj. } \mathrm{R}^{2} \\
(\text { wt } \%)\end{array}$ & R.S.E. \\
\hline 1 & 10 & 38 & $26.87 \pm 1.70$ & $-16.08 \pm 1.37$ & 0.88 & 0.51 \\
5 & 15 & 10 & $28.17 \pm 1.91$ & $-15.55 \pm 1.47$ & 0.96 & 0.17 \\
$5^{\text {a }}$ & 15 & 12 & $30.68 \pm 8.50$ & $-15.62 \pm 5.29$ & 0.80 & 0.11 \\
\hline
\end{tabular}

Notes: Data were collected in sessions 1 and 5 using analytical conditions of a $15 \mathrm{kV}$ accelerating voltage and $50 \mathrm{nA}$ beam current. $n$ is the number of measurements included in the fit. $m$ and $c$ are the slope and intercept, respectively, for $\mathrm{Fe}^{2+}=m \cdot(\mathrm{Fe} L \beta / \mathrm{Fe} L a)+c$. Adj. $\mathrm{R}^{2}$ is the adjusted $\mathrm{R}^{2}$. R.S.E. is the residual standard error on estimated $\mathrm{Fe}^{2+}$. Fits are for low-silica and aperalkaline glasses.

both the accelerating voltage and beam diameter, which limits the depth these electrons penetrate and the irradiated area, respectively. Overall, the rate of intensity change increases with increasing implanted electron density (i.e., decreased interaction volume and/or increased electron dosage).

\section{QUANTIFYING FE OXIDATION STATE: TIME- DEPENDENT RATIO FLANK METHOD}

\section{Calibration and errors}

Hofer and Brey (2007) found that the ratio of $\mathrm{Fe} L \beta_{\mathrm{f}} / \mathrm{Fe} L \alpha_{\mathrm{f}}$ correlated linearly with $\mathrm{Fe}^{2+}$ for garnets, with a small secondary dependence on $\mathrm{Fe}_{\mathrm{T}}$. Consequently, their coefficients ( $m$ and $c)$ of $\mathrm{Fe}^{2+}=m \cdot\left(\mathrm{Fe} L \beta_{\mathrm{f}} / \mathrm{Fe} L \alpha_{\mathrm{f}}\right)+c$ were dependent on $\mathrm{Fe}_{\mathrm{T}}$. Our data showed no improvement to the correlation between $\mathrm{Fe} L \beta_{\mathrm{f}} / \mathrm{Fe} L \alpha_{\mathrm{f}}$ and $\mathrm{Fe}^{2+}$ by allowing the coefficients to depend on $\mathrm{Fe}_{\mathrm{T}}$, therefore $m$ and $c$ are fitted without $\mathrm{Fe}_{\mathrm{T}}$ dependence using a weighted least-squares regression (weighted using error on independently constrained $\mathrm{Fe}^{2+}$ ). The lack of dependence on $\mathrm{Fe}_{\mathrm{T}}$ is likely because the composition of natural silicate glasses investigated here covers a much narrower range of $\mathrm{Fe}_{\mathrm{T}}$ compared to garnets ( $<18 \mathrm{vs} .64 \mathrm{wt} \% \mathrm{FeO}_{\mathrm{T}}$, respectively). The calibration curve is not constant between sessions (Fig. 11 and Table 5, and additional sessions in the Supplementary Material ${ }^{1}$ ), therefore a new calibration curve should be produced for each session.

It appears that low-silica and peralkaline glasses require different calibration curves (Fig. 11b), therefore these two sample groups were fitted separately. Using these different calibration curves, $\mathrm{Fe}^{2+} / \mathrm{Fe}_{\mathrm{T}}$ is replicated well for both compositions (Figs. $12 \mathrm{a}$ and $12 \mathrm{~b}$ ). Fe coordination also effects the $\mathrm{Fe} L$ lines but the coordination of silicate glasses is very similar (Cottrell et al. 2009). Instead, it may be that absorption within the glass of the $\mathrm{Fe} L$ lines is different between these two broad compositional groups due to their different compositions, although this was not observed for garnets (Hofer and Brey 2007). Compositional differences within the low-silica glasses may also explain the scatter observed in the calibration curves, but it is not possible to explore this fully using the current data set. It may be that errors on $\mathrm{Fe}^{2+} / \mathrm{Fe}_{\mathrm{T}}$ can be reduced by using compositionally matched glass standards. In practice such standards are unlikely to be available, therefore we recommend using standards with broadly similar compositions (i.e., low-silica or peralkaline) when using this technique.

A calibration curve could not be created for high-silica glasses PSB and $\mathrm{Y}$ as they cover a narrow range of $\mathrm{Fe}^{2+}(<2 \mathrm{wt} \%$ $\mathrm{Fe}^{2+}$ ). Their $\mathrm{Fe}^{2+} / \mathrm{Fe}_{\mathrm{T}}$ ratio are poorly replicated by the low-silica calibration curve (Fig. 12c) to which they lie more closely than the peralkaline calibration curve (Fig. 11b). This is likely due to their low Fe content $\left(\mathrm{FeO}_{\mathrm{T}}<3.3 \mathrm{wt} \%\right.$, except Y-L with 6.2 $\mathrm{wt} \%$ ), therefore this technique is unsuitable for low-Fe glasses (i.e., $\mathrm{FeO}_{\mathrm{T}}<5 \mathrm{wt} \%$ ).

The $\mathrm{Fe}^{2+} / \mathrm{Fe}_{\mathrm{T}}$ precision, using a residual standard error of $0.5 \mathrm{wt} \%$ on $\mathrm{Fe}^{2+}$ and $1 \%$ relative error on $\mathrm{FeO}_{\mathrm{T}}$, depends on the Fe concentration and oxidation state

$$
\mathrm{Fe}^{2+} / \mathrm{Fe}_{\mathrm{T}} \text { error }=\left(\mathrm{Fe}^{2+} / \mathrm{Fe}_{\mathrm{T}}\right)_{\mathrm{EPMA}} \cdot \sqrt{ }\left[\left(0.5 / \mathrm{Fe}^{2+}\right)^{2}+(0.01)^{2}\right]
$$

e.g., \pm 0.03 for $10 \mathrm{wt} \% \mathrm{FeO}_{\mathrm{T}}$ and $0.5 \mathrm{Fe}^{2+} / \mathrm{Fe}_{\mathrm{T}}$. The average accuracy for low-silica (43-56 wt $\% \mathrm{SiO}_{2}$ ) and peralkaline (70-76 


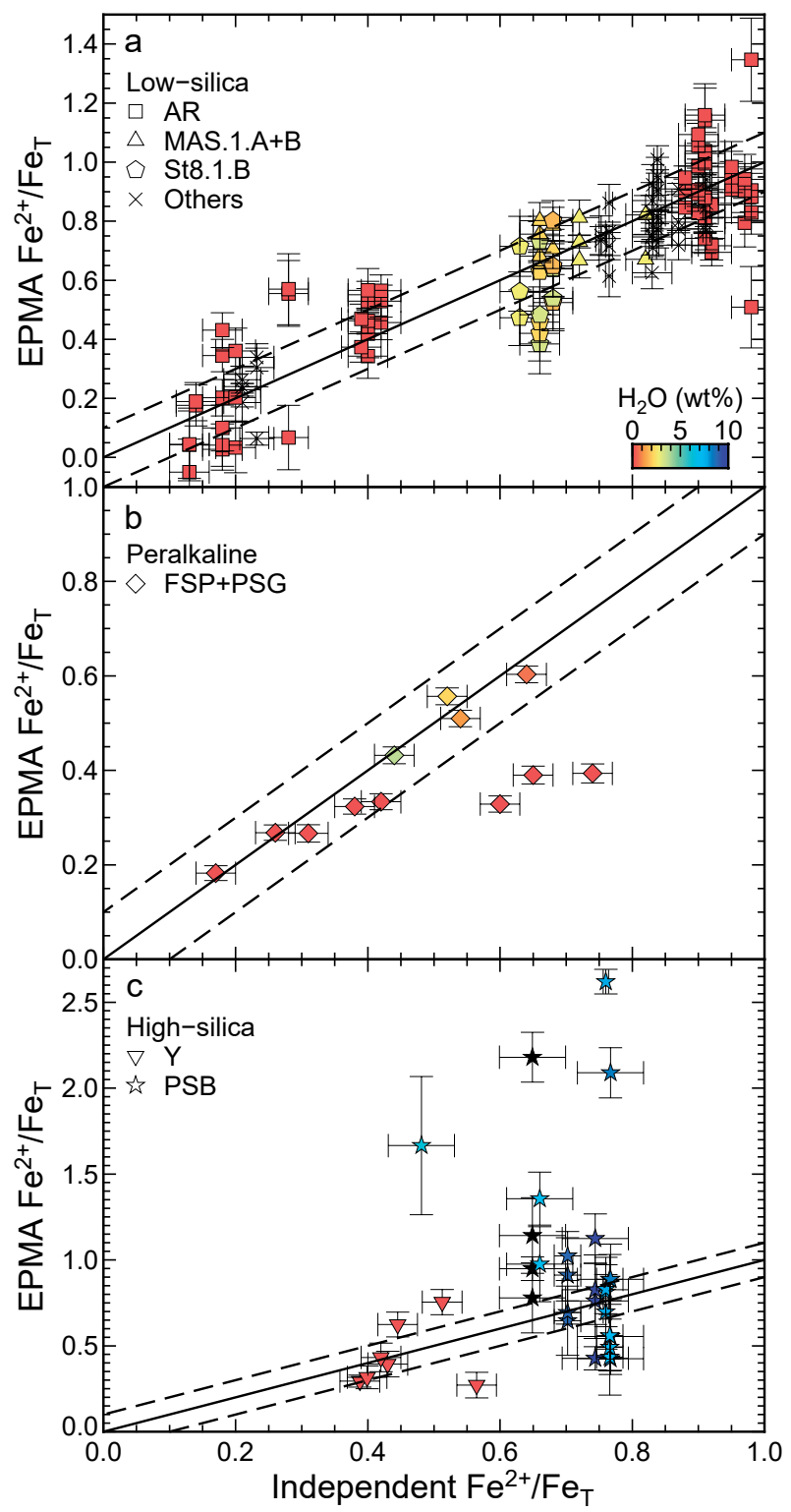

FIGURE 12. EPMA against independently constrained $\mathrm{Fe}^{2+} / \mathrm{Fe}_{\mathrm{T}}$ collected during all sessions for (a) low-silica (43-56 wt $\left.\% \mathrm{SiO}_{2}\right),($ b) peralkaline (FSP+PSG), and (c) high-silica (69-78 wt $\% \mathrm{SiO}_{2}$, using low-silica glass derived calibration curves) glasses, where symbol shape indicates average glass composition (Table 1) and color indicates $\mathrm{H}_{2} \mathrm{O}$. Analytical conditions were $15 \mathrm{kV}$ accelerating voltage, $50 \mathrm{nA}$ beam current, and $4-15 \mu \mathrm{m}$ beam diameter.

$\mathrm{wt} \% \mathrm{SiO}_{2}$ ) glasses with $5-18 \mathrm{wt} \% \mathrm{FeO}_{\mathrm{T}}$, and $0-4 \mathrm{wt} \% \mathrm{H}_{2} \mathrm{O}$, when the appropriate analytical conditions and calibration curves are used, is \pm 0.1 (Figs. 12a and 12b).

\section{Recommended analytical conditions}

Analytical conditions can be optimized according to the nature of any given sample as different conditions (beam diameter and current, total count time of a single analysis, and number of analyses averaged) can be used on the standards and unknowns, so long as the accelerating voltage and flank positions remain the same. Hofer and Brey (2007) showed that for garnets the optimum accelerating voltage is $15 \mathrm{kV}$; at lower and higher accelerating voltages the sensitivity of the flank method is reduced. For glasses, the sensitivity of the flank method also decreased at higher accelerating voltages (Figs. $3 b$ and 3c). An accelerating voltage of $15 \mathrm{kV}$ allows the composition of the sample to be analyzed, via conventional EPMA, without further calibration or beam focusing.

The error on the corrected $\mathrm{Fe} L \beta_{\mathrm{f}} / \mathrm{Fe} L \alpha_{\mathrm{f}}$ is a function of counting statistics, the fit of an exponential function to the change in $\mathrm{Fe} L \beta_{\mathrm{f}} / \mathrm{Fe} L \alpha_{\mathrm{f}}$ with time, and the number of analyses averaged. Counting statistics can be improved by using a higher beam current, but this can cause the rate of change to occur too quickly to be observed. Decreasing the beam diameter will also increase the rate of change, as seen here for high-silica glasses, but improves spatial resolution. Therefore, it is important to know the approximate composition of the target glass (e.g., by EDS analysis) to understand how quickly the change in Fe oxidation is likely to occur. If redox changes occur too quickly, the time-corrected $\mathrm{Fe} L \beta_{\mathrm{f}} / \mathrm{Fe} L \alpha_{\mathrm{f}}$ will be wrong leading to erroneous $\mathrm{Fe}^{2+} / \mathrm{Fe}_{\mathrm{T}}$ values. Our data at a $15 \mathrm{kV}$ accelerating voltage, $50 \mathrm{nA}$ beam current, $4 \mu \mathrm{m}$ beam diameter, and averaging 10 analyses produced a relative error on the corrected $\mathrm{Fe} L \beta_{\mathrm{f}} / \mathrm{Fe} L \alpha_{\mathrm{f}}$ of $\sim 3 \%$, and gave the flexibility to analyze various glass morphologies for hydrous low-silica glasses. A larger beam size $(10-15 \mu \mathrm{m}$ diameter) is needed to analyze high-silica samples containing sufficient iron (i.e., peralkaline) due to the rapid rate of oxidation, which unfortunately sacrifices spatial resolution. This technique may not be appropriate if samples contain fine-scale heterogeneities (e.g., nanolites), as the Fe coordination in these phases may differ to that in the glass.

\section{Further applications}

The TDR flank method presented here could be applied to other beam-sensitive samples. Electron probe induced dehydrogenation has been observed for kaersutitic amphibole, resulting in the underestimation of $\mathrm{Fe}^{2+} / \mathrm{Fe}_{\mathrm{T}}$ due to oxidation (Wagner et al. 2008). Wagner et al. (2008) showed the severity of damage correlated with analytical conditions and $\mathrm{H}_{2} \mathrm{O}$ content of the amphibole, in much the same way as shown here for silicate glasses. Therefore, applying the TDR flank method to amphiboles may provide robust $\mathrm{Fe}$ oxidation state estimates without sacrificing spatial resolution.

Oxidation and reduction of $\mathrm{S}$ have been observed during analysis of silicate glasses and anhydrite when using the $\mathrm{S} K \alpha$ peak shift to measure S oxidation state (Wallace and Carmichael 1994; Rowe et al. 2007; Wilke et al. 2011). Sulfur oxidation in silicate glasses appeared to follow an exponential trend and, as observed here, the estimate of redox state at time zero was found to agree with XANES measurements of the same sample (Wilke et al. 2011). Sulfur redox changes are controlled by similar factors to Fe such as initial S oxidation state (Rowe et al. 2007) and $\mathrm{H}_{2} \mathrm{O}$ content (Wilke et al. 2008). If a flank-type method was developed for S (Wilke et al. 2011), time-dependent measurements could also be applied, negating the need to move samples during analysis (Metrich and Clocchiatti 1996; Rowe et al. 2007), and thereby improving spatial resolution. 


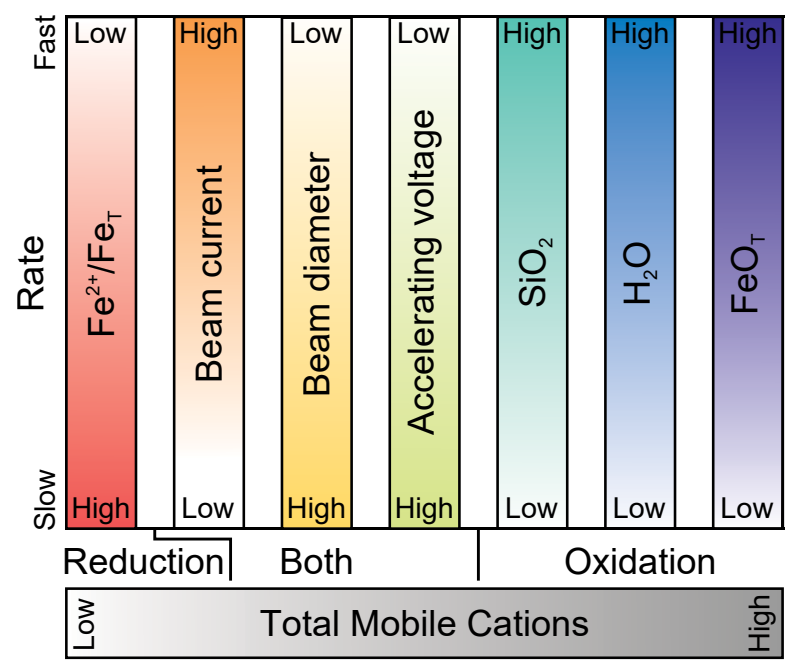

FIGURE 13. Schematic diagram showing the controls on the direction and rate of Fe redox changes in silicate glasses during electron beam irradiation.

\section{IMPLICATIONS}

Measuring the Fe oxidation state of silicate glasses allows estimation of oxygen fugacity prevailing during natural processes and in experiments. The time-dependent ratio flank method presented here combines the ability to measure the Fe oxidation state at high resolution with the utility of the electron probe. This will allow routine measurement of Fe oxidation state of melt inclusions and interstitial glass, previously hampered by the need for synchrotron access. Melt inclusions provide a unique insight into the pre-eruptive magma but studies have shown that the Fe oxidation state can be altered by degassing (e.g., Moussallam et al. 2014) and cooling (e.g., Hartley et al. 2017) post-entrapment, complicating their use as a proxy for oxygen fugacity. Hence, larger data sets generated due to easier access will allow the importance of these processes to be further investigated, although for some applications smaller errors will be required. Also, a better understanding of the analytical and compositional controls on redox changes during electron beam irradiation of silicate glasses (summarized in Fig. 13) can aid our understanding of glass structure and improve analytical routines.

\section{ACKNOWLEDGMENTS}

We thank Richard Hinton for his assistance at the NERC ion microprobe facility at the University of Edinburgh, U.K. (IMF560/0515). We thank Priscille Lesne, Charlotte Stamper, Peter Ulmer, and Liz Cottrell for providing samples. E.C.H. is supported by a NERC GW4+ DTP studentship from the Natural Environment Research Council (NE/L002434/1) and is thankful for the support and additional funding from CASE partner GNS Science, New Zealand. G.K. acknowledges support from the New Zealand Strategic Science Investment Fund. H.M.M., R.A.B., and D.D.G. were supported by the NSFGEO-NERC "Quantifying disequilibrium processes in basaltic volcanism" (NE/N018567/1). R.R.A. was supported by the German Science Foundation (DFG project AL 1189/6-1). We thank John Donovan and two anonymous reviewers for their helpful comments.

\section{REFERENCES CITED}

Almeev, R.R., Holtz, F., Ariskin, A.A., and Kimura, J.-I. (2013) Storage conditions of Bezymianny Volcano parental magmas: results of phase equilibria experiments at 100 and $700 \mathrm{MPa}$. Contributions to Mineralogy Petrology, $166,1389-1414$.

Almeev, R.R., Holtz, F., Koepke, J., Parat, F., and Botcharnikov, R.E. (2007) The effect of $\mathrm{H}_{2} \mathrm{O}$ on olivine crystallization in MORB: Experimental calibration at $200 \mathrm{MPa}$. American Mineralogist, 92, 670-674.

Bastin, G.F., and Heijligers, H.J.M. (1988) Contamination phenomena in the electron probe microanalyzer. Microbeam Analysis: Proceedings of the Annual Conference of the Microbeam Analysis Society, 23, 325.

Berndt, J., Liebske, C., Holtz, F., Freise, M., Nowak, M., Zienbenbein, D., Hurkuck, W., and Koepke, J. (2002) A combined rapid-quench and $\mathrm{H}_{2}$-membrane setup for internally heated pressure vessels: Description and application for water solubility in basaltic melts. American Mineralogist, 87, 1717-1726.

Blundy, J.D., Melekhova, E., Ulmer, P., Pichavant, M., Humphreys, M.C.S., Ziberna, L., Cerantolo, V., and Brooker, R.A. (2018) Iron redox equilibria in hydrous basaltic melts and $\mathrm{Fe}^{2+}-\mathrm{Mg}$ exchange between olivine and melt. EMPG-XVI.

Botcharnikov, R.E., Almeev, R.R., Koepke, J., and Holtz, F. (2008) Phase relations and liquid lines of descent in hydrous ferrobasalt: Implications for the Skaergaard Intrusion and Columbia River Flood Basalts. Journal of Petrology, 49, 1687-1727.

Bouhifd, M.A., Richet, P., Besson, P., Roskosz, M., and Ingrin, J. (2004) Redox state, microstructure and viscosity of a partially crystallized basalt melt. Earth and Planetary Science Letters, 218, 31-44.

Burgess, K.D., Stroud, R.M., Dyar, M.D., and McCanta, M.C. (2016) Submicrometer-scale spatial heterogeneity in silicate glasses using aberrationcorrected scanning transmission electron microscopy. American Mineralogist, 101, 2677-2688.

Buse, B., and Kearns, S. (2018) Quantification of olivine using Fe $L \alpha$ in Electron Probe Microanalysis (EPMA). Microscopy and Microanalysis, 24, 1-7.

Buse, B., Kearns, S., Clapham, C., and Hawley, D. (2016) Decontamination in the electron probe microanalysis with a peltier-cooled cold finger. Microscopy and Microanalysis, 22, 981-986.

Carmichael, I.S.E. (1991) The redox states of basic and silicic magmas: a reflection of their source regions? Contributions to Mineralogy and Petrology, $106,129-141$.

Cazaux, J. (1996) Electron probe microanalysis of insulating materials: Quantification problems and some possible solutions. X-ray Spectrometry, 25, 265-280.

Cooper, R.F., Fanselow, J.B., and Poker, D.B. (1996) The mechanism of oxidation of a basaltic glass: Chemical diffusion of network-modifying cations. Geochimica et Cosmochimica Acta, 60, 3253-3265.

Cottrell, E., Kelley, K.A., Lanzirotti, A., and Fischer, R.A. (2009) High-precision determination of iron oxidation state in silicate glasses using XANES. Chemical Geology, 268, 167-179.

Cottrell, E., Lanzirotti, A., Mysen, B., Birner, S., Kelley, K.A., Botcharnikov, R.E., Davis, F.A., and Newville, M. (2018) A Mössbauer-based XANES calibration for hydrous basalt glasses reveals radiation-induced oxidation of Fe. American Mineralogist, 103, 489-501.

Creighton, S., Stachel, T., Matveev, S., Höfer, H., McCammon, C., and Luth, R.W. (2009) Oxidation of the Kaapvaal lithospheric mantle driven by metasomatism. Contributions to Mineralogy and Petrology, 157, 491-504.

Creighton, S., Stachel, T., Eichenberg, D., and Luth, R.W. (2010) Oxidation state of the lithospheric mantle beneath Diavik diamond mine, central Slave craton, NWT, Canada. Contributions to Mineralogy and Petrology, 159, 645-657.

de Groot, F. (2001) High-resolution X-ray emission and X-ray absorption spectroscopy. Chemical Reviews, 101, 1779-1808.

Di Genova, D., Romano, C., Hess, K.U., Vona, A., Poe, B.T., Giordano, D., Dingwell, D.B., and Behrens, H. (2013) The rheology of peralkaline rhyolites from Pantelleria Island. Journal of Volcanology and Geothermal Research, 249, 201-216.

Di Genova, D., Romano, C., Giordano, D., and Alletti, M. (2014) Heat capacity, configurational heat capacity and fragility of hydrous magmas. Geochimica et Cosmochimica Acta, 1, 314-333.

Di Genova, D., Hess, K.U., Oryaelle Chevrel, M., and Dingwell, D.B. (2016) Models for the estimation of $\mathrm{Fe}^{3+} / \mathrm{Fe}_{\text {tot }}$ ratio in terrestrial and extraterrestrial alkali- and iron-rich silicate glasses using Raman spectroscopy. American Mineralogist, 101, 943-952.

Di Genova, D., Kolzenburg, S., Wiesmaier, S., Dallanave, E., Neuville, D.R., Hess, K.U., and Dingwell, D.B. (2017a) A compositional tipping point governing the mobilization and eruption style of rhyolitic magma. Nature, 552, 235-238.

Di Genova, D., Sicola, S., Romano, C., Vona, A., Fanara, S., and Spina, L. (2017b) Effect of iron and nanolites on Raman spectra of volcanic glasses: A reassessment of existing strategies to estimate the water content. Chemical Geology, 475, 76-86.

Di Muro, A., Métrich, N., Mercier, M., Giordano, D., Massare, D., and Montagnac, G. (2009) Micro-Raman determination of iron redox state in dry natural glasses: Application to peralkaline rhyolites and basalts. Chemical Geology, 259, 78-88.

Dingwell, D.B., and Virgo, D. (1987) The effect of oxidation state on the viscosity of melts in the system $\mathrm{Na}_{2} \mathrm{O}-\mathrm{FeO}-\mathrm{Fe}_{2} \mathrm{O}_{3}-\mathrm{SiO}_{2}$. Geochimica et Cosmochimica. Acta, 51, 195-205.

Enders, M., McCammon, C.A., Maresch, W.V., and Speer, D. (2000) Ferric/ferrous iron ratios in sodic amphiboles: Mössbauer analysis, stoichiometry-based model calculations and the high-resolution microanalytical flank method. Contributions to Mineralogy and Petrology, 140, 135-147. 
Fialin, M., and Wagner, C. (2012) Redox kinetics of iron in alkali silicate glasses exposed to ionizing beams: Examples with the electron microprobe. Journal of Non-Crystalline Solids, 358, 1617-1623.

Fialin, M., Wagner, C., Métrich, N., Humler, E., Galoisy, L., and Bézos, A. (2001) $\mathrm{Fe}^{3+} / \Sigma \mathrm{Fe}$ vs. $\mathrm{Fe} L \alpha$ peak energy for minerals and glasses: Recent advances with the electron microprobe. American Mineralogist, 86, 456-465.

Fialin, M., Bézos, A., Wagner, C., and Humler, E. (2004) Quantitative electron microprobe analysis of $\mathrm{Fe}^{3+} / \Sigma \mathrm{Fe}$ : Basic concepts and experimental protocol for glasses. American Mineralogist, 89, 654-662.

Fialin, M., Wagner, C., and Pascal, M.-L. (2011) Iron speciation using electron microprobe techniques: application to glassy melt pockets within a spinel lherzolite xenolith. Mineralogy Magazine, 75, 347-362.

Fuchs, P., Almeev, R.R., and Klugel, A. (2014) Experimental constraints on the formation of basanites-phonolite series (Cumbre Vieja, La Palma). Goldschmidt Conference Abstract.

Gopon, P., Fournelle, J., Sobol, P.E., and Llovet, X. (2013) Low-voltage electronprobe microanalysis of $\mathrm{Fe}-\mathrm{Si}$ compounds using soft X-rays. Microscopy and Microanalysis, 19, 1698-1708.

Hamilton, D.L., Burnham, C.W., and Osborn, E.F. (1964) The solubility of water and effects of oxygen fugacity and water content on crystallization in mafic magmas. Journal of Petrology, 5, 21-39.

Hartley, M.E., Shorttle, O., Maclennan, J., Moussallam, Y., and Edmonds, M. (2017) Olivine-hosted melt inclusions as an archive of redox heterogeneity in magmatic systems. Earth and Planetary Science Letters, 479, 192-205.

Hayward, C. (2011) High spatial resolution electron probe microanalysis of tephras and melt inclusions without beam-induced chemical modification. The Holocene, 22, 119-125.

Herd, C.D.K. (2008) Basalts as probes of planetary interior redox state. Reviews in Mineralogy and Geochemistry, 68, 527-554.

Hofer, H.E. (2002) Quantification of $\mathrm{Fe}^{2+} / \mathrm{Fe}^{3+}$ by electron microprobe analysisNew developments. Mössbauer Spectroscopy, 144/ 145, 239-248.

Hofer, H.E., and Brey, G.P. (2007) The iron oxidation state of garnet by electron microprobe: Its determination with the flank method combined with majorelement analysis. American Mineralogist, 92, 873-885.

Hofer, H.E., Brey, G.P., Schulz-Dobrick, B., and Oberhansli, R. (1994) The determination of the oxidation state of iron by the electron microprobe. European Journal of Mineralogy, 6, 407-418.

Humphreys, M.C.S., Kearns, S.L., and Blundy, J.D. (2006) SIMS investigation of electron-beam damage to hydrous, rhyolitic glasses: Implications for melt inclusion analysis. American Mineralogist, 91, 667-679.

Jarosewich, E., Nelen, J.A., and Norberg, J.A. (1980) Reference samples for electron microprobe analysis. Geostandards and Geoanalytical Research, 4, 43-47.

Klimm, K., Kohn, S.C., O’Dell, L.A., Botcharnikov, R.E., and Smith, M.E. (2012) The dissolution mechanism of sulphur in hydrous silicate melts. I: Assessment of analytical techniques in determining the sulphur speciation in iron-free to iron-poor glasses. Chemical Geology, 322-323, 237-249.

Kress, V.C., and Carmichael, I.S.E. (1991) The compressibility of silicate liquids containing $\mathrm{Fe}_{2} \mathrm{O}_{3}$ and the effect of composition, temperature, oxygen fugacity and pressure on their redox states. Contributions to Mineralogy and Petrology, 108, 82-92.

Lafuente, B., Downs, R.T., Yang, H., and Stone, N. (2015) The power of databases: The RRUFF project. In T. Armbruster and R.M. Danisi, Eds., Highlights in Mineralogical Crystallography, p. 1-30. De Gruyter.

Lamb, W.M., Guillemette, R., Popp, R.K., Fritz, S.J., and Chmiel, G.J. (2012) Determination of $\mathrm{Fe}^{3+} / \mathrm{Fe}$ using the electron microprobe: A calibration for amphiboles. American Mineralogist, 97, 951-961.

Lesne, P., Kohn, S.C., Blundy, J.D., Witham, F., Botcharnikov, R.E., and Behrens, H. (2011) Experimental simulation of closed-system degassing in the system basalt- $\mathrm{H}_{2} \mathrm{O}-\mathrm{CO}_{2}-\mathrm{S}-\mathrm{Cl}$. Journal of Petrology, 52, 1737-1762.

Lineweaver, J.L. (1963) Oxygen outgassing caused by electron bombardment of glass. Journal of Applied Physics, 34, 1786

Malaspina, N., Scambelluri, M., Poli, S., Van Roermund, H.L.M., and Langenhorst, F. (2010) The oxidation state of mantle wedge majoritic garnet websterites metasomatised by C-bearing subduction fluids. Earth and Planetary Science Letters, 298, 417-426.

Matjuschkin, V., Brey, G.P., Höfer, H.E., and Woodland, A.B. (2014) The influence of $\mathrm{Fe}^{3+}$ on garnet-orthopyroxene and garnet-olivine geothermometers. Contributions to Mineralogy and Petrology, 167, 972.

McCammon, C.A. (1999) Methods for determination of $\mathrm{Fe}^{3+} / \Sigma \mathrm{Fe}$ in microscopic samples. In J.L. Gurney, J. Gurney, M.D. Pascoe, and S.H. Richardson, Eds., Proceedings of the VIIth International Kimberlite Conference, P.H. Nixon Volume, p. 540-544.

Metrich, N., and Clocchiatti, R. (1996) Sulfur abundance and its speciation in oxidized alkaline melts. Geochimica et Cosmochimica Acta, 60, 4151-4160.

Morgan, G.B. VI, and London, D. (2005) Effect of current density on the electron microprobe analysis of alkali aluminosilicate glasses. American Mineralogist,
90, 1131-1138

Moussallam, Y., Oppenheimer, C., Scaillet, B., Gaillard, F., Kyle, P., Peters, N. Hartley, M.E., Berlo, K., and Donovan, A. (2014) Tracking the changing oxidation state of Erebus magmas, from mantle to surface, driven by magma ascent and degassing. Earth and Planetary Science Letters, 393, 200-209.

Mysen, B.O., Virgo, D., and Seifert, F.A. (1982) The structure of silicate melts: Implications for chemical and physical properties of natural magma. Reviews in Geophysics, 20, 353.

Nielsen, C.H., and Sigurdsson, H. (1981) Quantitative methods for electron microprobe analysis of sodium in natural and synthetic glasses. American Mineralogist, 66, 547-552.

Nishida, T. (1995) Mössbauer effect in inorganic glasses. Hyperfine Interactions, $95,23-39$.

Okumura, S., and Nakashima, S. (2006) Water diffusion in basaltic to dacitic glasses. Chemical Geology, 227, 70-82.

Potapkin, V., Chumakov, A.I., Smirnov, G.V., Celse, J.-P., Rüffer, R., McCammon, C., and Dubrovinsky, L. (2012) The ${ }^{57} \mathrm{Fe}$ Synchrotron Mössbauer Source at the ESRF. Journal of Synchrotron Radiation, 19, 559-569.

Reed, S.J. (1975) Electron Microprobe Analysis. Cambridge University Press.

Riker, J.M.J., Blundy, J.D., Rust, A.C., Botcharnikov, R.E., and Humphreys, M.C.S (2015) Experimental phase equilibria of a Mount St. Helens rhyodacite: a framework for interpreting crystallization paths in degassing silicic magmas. Contributions to Mineralogy and Petrology, 170, 6.

Rowe, M.C., Kent, A.J.R., and Nielsen, R.L. (2007) Determination of sulfur speciation and oxidation state of olivine hosted melt inclusions. Chemical Geology, 236, 303-322.

Schuessler, J.A., Botcharnikov, R.E., Behrens, H., Misiti, V., and Freda, C. (2008) Oxidation state of iron in hydrous phono-tephritic melts. American Mineralogist, 93, 1493-1504

Smith, D.G.W., and O'Nions, R.K. (1971) Investigations of the $\mathrm{L}_{\mathrm{IL}}$, X-ray emission spectra of $\mathrm{Fe}$ by the electron microprobe Part I: Some aspects of the Fe $\mathrm{L}_{\mathrm{II}, \text { III }}$ spectra from metallic iron and haematite. Journal of Physics D: Applied Physics, 4, 147-159.

Stamper, C.C., Melekhova, E., Blundy, J.D., Arculus, R.J., Humphreys, M.C.S., and Brooker, R.A. (2014) Oxidised phase relations of a primitive basalt from Grenada, Lesser Antilles. Contributions to Mineralogy and Petrology, 167, 954

Ulmer, P. (1989) The dependence of the $\mathrm{Fe}^{2+}-\mathrm{Mg}$ cation-partitioning between olivine and basaltic liquid on pressure, temperature and composition. Contributions to Mineralogy and Petrology, 101, 261-273.

Vicenzi, E.P., Green, T., and Sie, S. (1994) Effect of oxygen fugacity on traceelement partitioning between immiscible silicate melts at atmospheric pressure: A proton and electron microprobe study. Chemical Geology, 117, 355-360.

Wagner, C., Deloule, E., Fialin, M., and King, P.L. (2008) Dehydrogenation of kaersutitic amphibole under electron beam excitation recorded by changes in $\mathrm{Fe}^{3+} / \Sigma \mathrm{Fe}$ : An EMP and SIMS study. American Mineralogist, 93, 1273-1281.

Wallace, P.J., and Carmichael, I.S.E. (1994) S speciation in submarine basaltic glasses as determined by measurements of $\mathrm{S} K \alpha \mathrm{X}$-ray wavelength shifts. American Mineralogist, 79, 161-167.

Wengorsch, T., Fuchs, P., Almeev, R.R., and Klugel, A. (2012) Revealing true liquid compositions for natural phonolites from Cumbre Vieja volcano, La Palma Island. EMPG-XIV, 143.

Wilke, M. (2005) Fe in magma-An overview. Annals of Geophysics, 48, 609-617.

Wilke, M., Jugo, P.J., Klimm, K., Susini, J., Botcharnikov, R.E., Kohn, S.C., and Janousch, M. (2008) The origin of $\mathrm{S}^{4+}$ detected in silicate glasses by XANES. American Mineralogist, 93, 235-240.

Wilke, M., Klimm, K., and Kohn, S.C. (2011) Spectroscopic studies on sulfur speciation in synthetic and natural glasses. Reviews in Mineralogy and Geochemistry, 73, 41-78.

Zhang, C., Almeev, R.R., Hughes, E.C., Borisov, A., Wolff, E., Hofer, H.E. Botcharnikov, R.E., and Koepke, J. (2018) Electron microprobe technique for the determination of iron oxidation state in silicate glasses. American Mineralogist, 103, 1445-1454.

MANUSCRIPT RECEIVED MARCH 9, 2018

MANUSCRIPT ACCEPTED MAY 5, 2018

MANUSCRIPT HANDLED BY IAN SWAINSON

\section{Endnote:}

${ }^{1}$ Deposit item AM-18-96546, Supplemental Material. Deposit items are free to all readers and found on the MSA web site, via the specific issue's Table of Contents (go to http://www.minsocam.org/MSA/AmMin/TOC/2018/Sep2018 data/ Sep2018_data.html). 